Portland State University

PDXScholar

\title{
Theater Over Textbooks: How a Neuroscience Outreach Group Utilizing Art in S.T.E.M. Provides Cost-Effective Strategies in Tackling the United States Education Gap
}

\author{
Camden Grant Howard \\ Portland State University \\ William Griesar \\ Portland State University
}

Follow this and additional works at: https://pdxscholar.library.pdx.edu/honorstheses

Part of the Art Education Commons, Curriculum and Social Inquiry Commons, Educational Assessment, Evaluation, and Research Commons, Education Policy Commons, and the Science and Mathematics Education Commons Let us know how access to this document benefits you.

\section{Recommended Citation}

Grant Howard, Camden and Griesar, William, "Theater Over Textbooks: How a Neuroscience Outreach Group Utilizing Art in S.T.E.M. Provides Cost-Effective Strategies in Tackling the United States Education Gap" (2020). University Honors Theses. Paper 933.

https://doi.org/10.15760/honors.958

This Thesis is brought to you for free and open access. It has been accepted for inclusion in University Honors Theses by an authorized administrator of PDXScholar. Please contact us if we can make this document more accessible: pdxscholar@pdx.edu. 


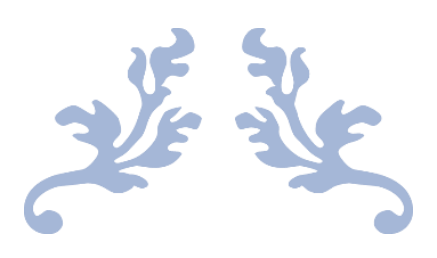

\section{THEATER OVER}

TEXTBOOKS:

How a Neuroscience Outreach Group Utilizing Art in S.T.E.M. Provides Cost-Effective Strategies in

Tackling the United States Education Gap

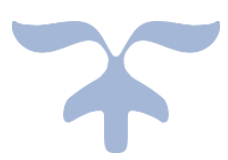

CAMDEN GRANT HOWARD

WILLIAM GRIESAR, PH.D.

Portland State University Honors College 
How a Neuroscience Outreach Group Utilizing Art in S.T.E.M. Provides Cost-Effective Strategies in Tackling the United States

Education Gap Grant Howard 1

\section{Contents}

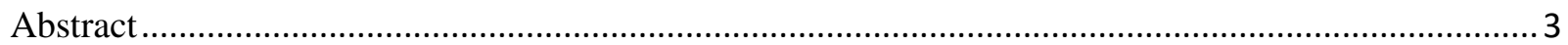

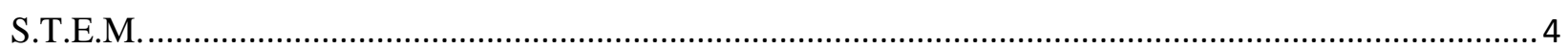







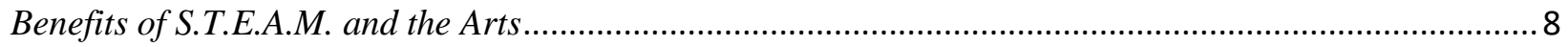

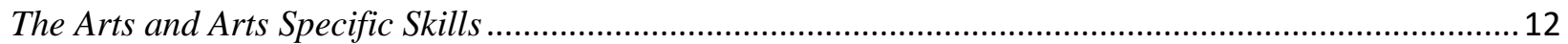

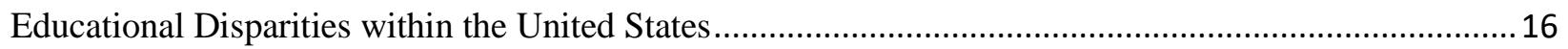

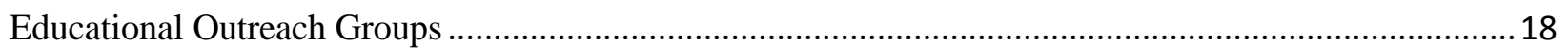

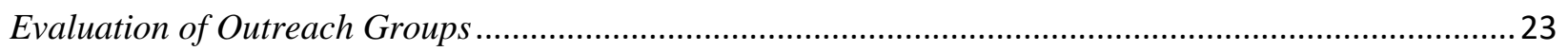



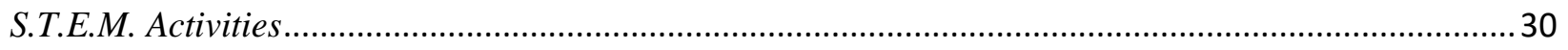

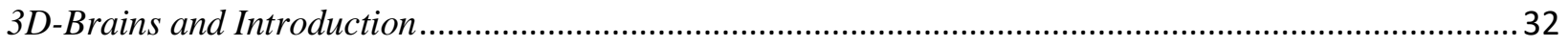

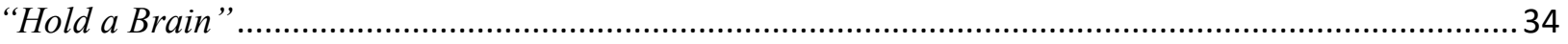

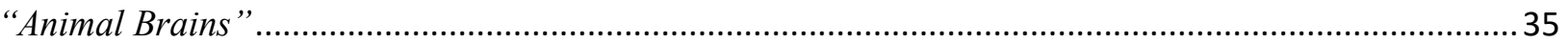

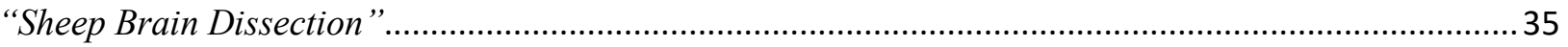



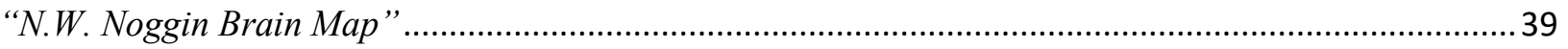

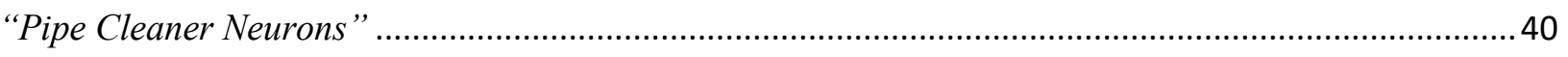

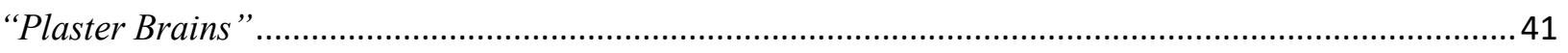

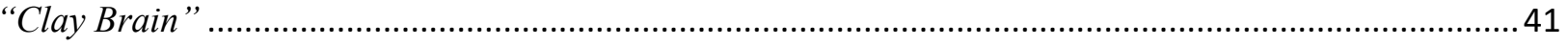

"Found Neuron Project" ........................................................................................................... 42

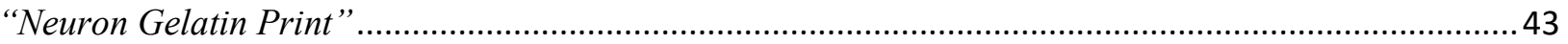





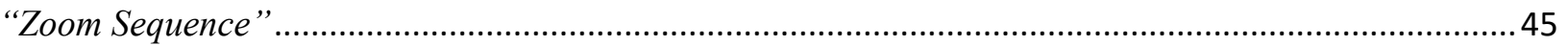

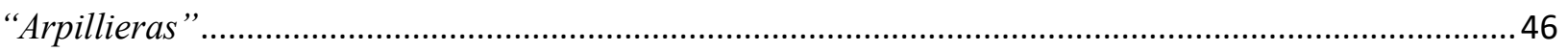

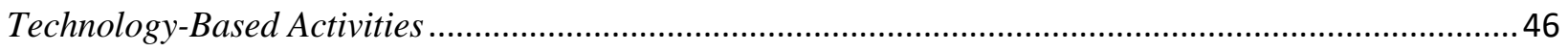



"Human to Human Interface "...................................................................................................... 47 
How a Neuroscience Outreach Group Utilizing Art in S.T.E.M. Provides Cost-Effective Strategies in Tackling the United States

Education Gap Grant Howard 2



"Brain Game” and Other Worksheets ................................................................................48

The Art of Inquiry \& N.W. Noggin ..................................................................................

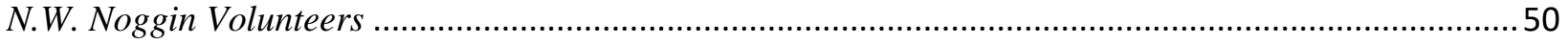




How a Neuroscience Outreach Group Utilizing Art in S.T.E.M. Provides Cost-Effective Strategies in Tackling the United States

\section{Abstract}

The purpose of this thesis was to summarize the relevant research for the evaluation of a S.T.E.A.M.-based, grassroots, neuroscience outreach group called 'N.W. Noggin.' This paper discusses the benefits and skills of S.T.E.M. in learning, the benefits and skills of S.T.E.A.M. in learning, educational disparities within the United States, how educational outreach groups are currently assessed as well as more innovative arts-based and inquiry-based alternative assessments of student knowledge. This paper then focuses on the nonprofit N.W. Noggin to discuss their goals and activities and possible options for program assessment. This thesis also discusses how they fulfill their civic duty as an educational outreach group, both to underserved communities and to their own outreach volunteers. This thesis will hopefully provide a solid foundation for outreach assessment, both for N.W. Noggin and other S.T.E.M./S.T.E.A.M. outreach groups, while encouraging a more interdisciplinary approach to inclusive education. 


\section{S.T.E.M.}

\section{S.T.E.M. Benefits}

The fields of Science, Technology, Engineering, and Mathematics (S.T.E.M.) continue to rise in popularity as more global communities recognize the necessity of S.T.E.M. in solving many current international issues. According to the Renewable Resources Coalition, the lens of S.T.E.M. can address most challenges that society faces today. As such, the future of most careers will center in S.T.E.M. sectors.

Careers in the domain of S.T.E.M reward highly in terms of personal income and social prestige. Despite this status, S.T.E.M. remains more objective and reliant on individual performance compared to other disciplines. Therefore, due to the impartial process of criteria evaluation, sociology researchers believe that the academic discipline of S.T.E.M. holds more potential for individual social mobilization for all learners. (David et al., 2011; Carnevale et al., 2013)

According to UC Davis' Office of the Provost, a predicted $80 \%$ of jobs in the next decade require expertise based in S.T.E.M.. In fact, according to a study by the Science Foundation Arizona (S.F.A.Z.), 1.7 jobs exist for every one unemployed person in S.T.E.M. disciplines compared to one job for every 4.1 unemployed people in non-S.T.E.M. fields. According to the Annual Recovery Report: Job Growth and Education Requirements Through 2020 released by the Center on Education and the Workforce at Georgetown University, there will be 55 million job openings, driven in part by the upcoming tidal wave of retirees from the 'Baby Boom Generation.' However, $65 \%$ of all jobs will require some form of postsecondary education. As a result, a predicted 5 million job openings may remain unfilled in the United States due to the lack of a qualified labor force. Many companies, in recognition of the field's significance, began investing in educational initiatives in hopes of filling in expected gaps in employment. 
Individuals not working careers in S.T.E.M. still benefit from learning skills typical to that vocation discipline. Fieldwork conducted by Siekmann \& Korbel (2016, pgs. 26-27) indicates that S.T.E.M. applies to other fields but not vice versa. The universal quality of S.T.E.M. skills means someone with a degree in S.T.E.M. could transfer expertise to a career outside of their degree focus. However, someone with a degree in a non-S.T.E.M.-related sphere may struggle to do the same with their degree and skillset. S.T.E.M. aptitude, such as research, data analysis, problem-solving, critical thinking, adaptability, inquiry, and innovation, remain in high demand and pertain to other degree focuses.

\section{S.T.E.M. Skills}

"Research" and "data analysis" prowess relate to a variety of fields outside of S.T.E.M., including journalism, financial investing, and some history branches (i.e., academic library sciences, archeology, art history). They assist in everyday situations, from deciding which brand at the store to purchase based on ethics to choosing a political candidate to support. In an age plagued by misinformation, the ability to carry out individual research and analyze presented data to discern fact from fiction is vital.

The ability to identify a problem, select alternatives for a potential solution, and then implement a resolution defines the term "problem-solving." "Critical thinking" is defined as "the analysis of an issue or situations and the facts, data, or evidence related to it." Critical thinking involves an individual's ability to make logical and informed decisions based on presented information or observations (Estrad, 2018). Both sets of abilities offer value for all fields, and S.T.E.M. mainly builds to their acquirement. A study administered by Soros et al. (2018), for example, found a significant difference between both the problem solving and critical thinking capabilities of students before and after the implementation of a S.T.E.M. Education Plan.

An individual's ability to keep up with continually changing industries and stay proficient in technology is known as "adaptability." Adaptability means not only responding to new situations flexibly but also recovering and adjusting when blunders occur. Whether during a chemistry experiment or an art 
project, if an individual hopes to make achievements within their field, they must learn from mistakes and move on.

Another crucial skill, which S.T.E.M. nurtures, centers around the ability to inquire, to critically think, and challenge societal and academic standards. "Inquiry" often informs "innovation," the foundation for economic growth and a vital force in propelling humanity forwards, from the development of vaccines to smartphones. Currently, sociology and neuroscience researchers alike debate whether an individual can learn creativity and innovation, if they depend on biology, or if a combination of genetics and epigenetics comes into play. A popular theory in Europe, as reported on by Fjortoft, Gettig, \& Verdone (2018), dictates that other S.T.E.M. skills supplement creativity. However, they also turn teaching away from knowledge-based testing assessments and allow teachers to instruct more imaginatively. According to Blouin et al. (2009), when focused on innovation as the outcome, educators themselves acted flexibly with lesson plans and engagingly delivered the material. Think of various inventions and experiments throughout history: innovation played a crucial role in all of them, and it occupies a similar role for advocates today. (Wandari et al., 2018; Perignat \& Katz-Buonincontro, 2019; Thuneberg et al., 2018; Organization for Economic Cooperation and Development, 2016; Bueno, 2018; Foster \& Yaoyuneyong, 2016)

Most of the younger generation's preparation for more technical S.T.E.M. skills is severely lacking. According to the American College Testing (A.C.T.), of the students who took their college entrance test in 2017, only $21 \%$ reached the 'ACT STEM Benchmark.' ACT cites the score of 26 as representing the level of readiness required for a pupil to hold a $50 \%$ chance of receiving a " $\mathrm{B}$ " in a firstyear S.T.E.M. course at most four-year institutions. Underserved learner populations, defined by the ACT as either belonging to a racial or ethnic minority, coming from a low-income household, not having immediate family with college degrees, or a combination of two or all three, faced much more difficulty in meeting this benchmark. Only $11 \%$ of learners meeting facing one disparity (i.e., racial/ethnic minority, low-income household, or first generation college student), 5\% of learners facing two disparities 
(i.e., racial/ethnic minority and low-income household, racial/ethnic minority and first generation college student, low-income household and first generation college student), and $2 \%$ of learners facing all three disparities outlined by the ACT (i.e., racial/ethnic minority, low-income household, and first-generation college student) this benchmark. A different study by Dr. Shelby Robertson found that less than $40 \%$ of scholars entering college plan to obtain degrees in S.T.E.M. while the awarding of degrees in S.T.E.M. is estimated at only about $19 \%$. Hence, understanding how best to prepare children and adolescents with the best tools possible to tackle complex global issues remains vital. (Ali, 2014; Dunn et al., 2012; Hwang \& Taylor, 2016)

As S.T.E.M. sees a rise in both popularity and impact, arts and humanities continue to receive less funding. Despite this, higher education institutions see high enrollment within degrees related to so-called "soft sciences" within arts and humanities, especially amongst specific populations facing educational disparities. According to the 'Racial/Ethnic Distribution of Bachelor's Degrees in the Humanities' released by the American Academy of Arts \& Sciences (2017), 26.1\% of underserved racial and ethnic learners received degrees in behavioral and social sciences and $25.5 \%$ received degrees in "other" fields (i.e., criminal justice, social work). In contrast, only $15.5 \%$ received degrees in engineering. As this disparity increases and interest in S.T.E.M. drops, Science, Technology, Engineering, Arts, and Mathematics (S.T.E.A.M.) allows for a solution that continues to engage diverse students in the arts and humanities while encouraging their concurrent interest and involvement in S.T.E.M.. 
How a Neuroscience Outreach Group Utilizing Art in S.T.E.M. Provides Cost-Effective Strategies in Tackling the United States

\section{S.T.E.A.M.}

\section{Benefits of S.T.E.A.M. and the Arts}

S.T.E.A.M. officially rose to popularity amongst academic establishments in the early 2000 s as an attempt to encourage and better prepare pupils for a future rooted in S.T.E.M.. S.T.E.A.M. falls under the concept of "Arts Integration," or "the infusion of visual and performing arts activities in non-arts subjects" (Lorimer, 2011). The incorporation of the arts offers a sense of relevance for students who might otherwise feel disconnected from S.T.E.M. subjects. It empowers them to take on more daunting tasks, such as more significant, long-term projects. Misconceptions exist: for example, the idea that practitioners of fine arts and S.T.E.M. subjects cannot collaborate and that scientists lack artistic capabilities. Fine arts provide space to nurture competence valued in S.T.E.M. and, when given opportunities to do so, graduate scholars in S.T.E.M. thrive in creative roles and perform better in their fieldwork. S.T.E.A.M. recognizes fine arts and S.T.E.M. not as competing forces but rather as critical components to building competence around innovation and independent thinking. On that account, they ideally should incorporate jointly to ensure benefits from both approaches. (Perignat \& KatzBuonincontro, 2019; Hardiman, 2018; Segarra et al., 2018)

When schools undergo assessment for funding based on how students score on annual national tests, the consequences of this issue become more apparent. Teachers limit their lesson focus during specific periods of a single school year instead of covering more personally relevant material. When schools centralize rote memorization as the main component of student knowledge evaluation, they enable the system to cling to more traditional styles of teaching. Consequentially, schools put in limited effort to make space available for more innovative, arts-integrated approaches.

Perhaps teachers should place mastery as the end goal to allow for focus on long-term retention and skills. Unlike rote memorization in traditional classrooms, S.T.E.A.M. allows pupils to identify their unique interests, experiences, motivations, and modes of thinking as opposed to "experts" or authorities 
How a Neuroscience Outreach Group Utilizing Art in S.T.E.M. Provides Cost-Effective Strategies in Tackling the United States Education Gap Grant Howard 9

dictating what should be most important to them. Furthermore, one evaluates the arts through standards that provide evidence of understanding as opposed to the binary focus of standardized testing, a possible reason for the recent devaluation of the arts and interdisciplinary utilization in our education system which relies heavily on standardized testing assessments. S.T.E.A.M. within the classroom grants open discussions around paramount concepts like trust and improved communication and writing adeptness due to increased motivation and creativity. It engages multiple senses during the learning process, which enables a more memorable experience (Perignat \& Katz-Buonincontro, 2019; Catchen, 2013; Hardiman, 2003; Hardiman, 2010).

Schools and society alike value strengths and knowledge associated with S.T.E.A.M. and other interdisciplinary learning practices as art enhances the learning and teaching of scientific concepts for a multitude of reasons. Firstly, it holds the ability to teach and supplement skills based on visualization, problem-solving, and communication. Arts engage skills in semantic elaboration, cue-prompted information generation, enactment, vocal production, emotional arousal, and pictorial representation. Hardiman $(2003,2010)$ proposed enhanced student engagement apparent in the arts allows for long-term knowledge retention. Arts must possess emotional meaning to impact students in the long-term, making them a meaningful aid during the learning process. When this occurs, the arts' emotional complexity allows for a variety of benefits. Arts and arts integration require decoding and interpretation. This complexity prompts students to think intricately and thoughtfully while engaging in deeper relational learning. According to Struyf \& Blockeel (2010), "relational learning refers to learning in a context where there may be relationships between learning examples, or where these examples may have a complex internal structure (i.e., consist of multiple components and there may be relationships between these components). In other words, the "relational" may refer to both an internal or external structure describing the examples." Relational learning relies heavily on the emotional arousal present in arts; Rinne et al. (2011) maintain this nurtures persistence and reflectiveness, tools linked to academic success. Regarding the learning process, art plays a significant role in every step, from supplementing material during the 
preliminary stage to brainstorming and working through new information, to reflection and communication at the final step (Segarra et al., 2018).

Rinne et al. (2011) suggest the following for reshaping traditional classroom activities into 'Arts Integrated' ones:

- worksheets with room for written answers convert to worksheets with space to draw answers;

- defining vocabulary words via written expression convert to student drawing to match vocabulary meanings;

- $\quad$ silent reading of textbooks converts to silent reading stories based on lesson material;

- out loud reading of textbooks converts to acting out scripts based on lesson material;

- group presentations convert to student-driven sketches for projects;

- reviews and exams convert to art exhibits and portfolios.

Art also engages creativity, a complex and multifaceted concept, making the standardized defining or assessing of the arts a challenge. Rhodes (1963) claims that "the context of one's personality, the products one can produce, the environment one is in when generating a creative product, and one's mode of thinking when creating an original product or response" contribute to an individual's creativity. Creativity benefits specific executive function processes. These include cognitive functions (i.e., maintaining working memory, impulse control, perceptual, focus, and attention shifts) that allow for recall, planning, knowledge application, and problem-solving. Unique thinking leads to practicing the generation of new ideas, the consideration of differing viewpoints, finding connections between noncorrelated concepts, and the ability to disassemble others' ideas to inform innovation. (Gregory et al., 2013; Harmond, 2016)

Some researchers conclude that creativity cannot occur without expertise. "Expertise" can be "routine" (i.e., knowledge of task procedures that allow an individual to perform efficiently) or "adaptive" (i.e., mastery of "routine" expertise that allows an individual to understand why procedures work, modify them, and innovate based on them). Crawford \& Brophy (2006) suggest setting "adaptive" expertise as 
How a Neuroscience Outreach Group Utilizing Art in S.T.E.M. Provides Cost-Effective Strategies in Tackling the United States Education Gap Grant Howard 11

the goal due to its engagement of problem-solving and creative skills essential for innovation. Situationally motivated and real-life application activities extend opportunities to students to apply their current expertise flexibly and build up confidence. Rinne et al. (2011) also suggest utilizing "discover" activities during the initial process that allow students to teach information on their own, necessary for building expertise, long-term retention, and higher cognitive efforts. McDaniel and Bugg (2012) support the concept that unusualness produces higher long-term retention, thus building expertise.

Creativity builds the foundation for unique learning experiences, which are memorable due to the arousal of emotion. McGough (2004) found that emotional arousal associated with the limbic system, particularly the amygdala, plays an essential role in attention and focus. Research suggests emotional arousal causes changes in attention and focus during memory coding in addition to boosting immediate information recall, leading to higher long-term retention. Rinne et al. (2011) concluded that emotionally arousing information is more memorable than emotionally neutral information and that the amygdala (i.e., fight or flight) plays a vital role in the learning process. Considering the current rates of P.T.S.D. in K-12 schooling, arts integration seems an excellent first step for teachers aiming for a trauma-aware learning setting.

In general, the arts provide a variety of benefits. In the context of the classroom, using imagebased arts during preliminary instruction produces the "picture superiority effect." The "picture superiority effect" refers to the fact that the brain "dual codes" (i.e., engages multiple functional brain areas) information presented via visualization. As such, long-term retention of knowledge derived from imagery lasts longer than information presented either verbally or in written form. Information conveyed via drawings successfully conveys student knowledge, offering an accessible alternative to traditional evaluations. Teachers do not typically receive training in nurturing creativity within the classroom, and many conceptual ideas like creativity require heightened student training. As such, researchers suggest an interdisciplinary approach to classroom activities to simplify the initial process and build essential skills. 
How a Neuroscience Outreach Group Utilizing Art in S.T.E.M. Provides Cost-Effective Strategies in Tackling the United States

Education Gap

Grant Howard 12

In addition to these different benefits, different art types hold the potential to teach and supplement different skills valued in S.T.E.M. depending on the nature of the art. (Gregory et al., 2013)

\section{The Arts and Arts Specific Skills}

As previously mentioned, assessment should consider drawing, but it also supplements other parts of the learning process. Sketching promotes close observations eliciting relationships between function and form, serves as a good model for problem-solving, and aids in faster learning and a more in-depth understanding of the material. Arts such as painting allow for constraints and structure while giving learners' agency to self-express and convey expertise (Segarra et al., 2018; Cutcher \& Bayel, 2016).

Video game design offers the benefits of learning technology while being creative in a team. Much of game design relies on computer skills but also on imagination and innovation. Teams must create storyboards and set goals before starting the actual project creation. Artists create images from the storyboard by hand and on the computer via various arts programs (i.e., Adobe Illustrator). Coders then systemize numbers in the correct order to represent gaming graphics and organization of how the games work and play for users. (Uluay \& Dogan, 2016).

Studying art history offers interdisciplinary benefits from both arts and history areas. Replacing textbooks with period art critiques during the supplementary stage for engagement of relational learning or at the assessment stage prompts intensified student evaluation and thought. Connecting art history with S.T.E.M. subjects offers complex interdisciplinary learning, in return promoting a deeper understanding of lesson material itself and its context (Gregory et al., 2013).

Music also holds great potential within the classroom, in part due to its natural reliance on repetition. Repetition establishes both familiarity and precision; music makes rehearsal of information easier to grasp both in terms of benefitting understanding of information and long-term retention. Vaughn (2000) found that music training improves spatiotemporal reasoning necessary for many forms of mathematics skills. Other researchers (Dolgan, 2018; Rose et al., 2018) suggest learning to play an 
How a Neuroscience Outreach Group Utilizing Art in S.T.E.M. Provides Cost-Effective Strategies in Tackling the United States

Education Gap

Grant Howard 13

instrument may benefit students with neurodevelopmental disorders. Students with Autism Spectrum

Disorder (A.S.D.) can learn to connect with emotion present in music while simultaneously connecting to structure present in the music. Students with Attention-Deficit/Hyperactivity Disorder (AD/HD) may benefit from the active engagement of music, both physically and mentally. Gregory et al. (2013) discuss the brain's process of "dual-coding," or engaging multiple functional brain regions during the learning process, more complex instruction methods of knowledge such as through the fine arts, including music. Because of this higher level of engagement, Dolgan (2018) have found music to strengthen focus and attention capabilities while helping relieve symptoms of hyperactivity. Additionally, music enhances motor capabilities as well as attention and focus in both populations. (Janzen \& Thaut, 2018; Rose et al., 2018; Dolgan, 2018)

Adding physical movement to music (e.g., dance) can also yield several benefits, in part because of the dance's complexity and the usage of multiple art forms. Performative dance communicates complicated concepts in a more engaging, visual, and playful manner. It conveys a variety of emotions depending on certain factors (i.e., emphasis/usage of the body, music tempo/intensity/rhythm, dance style/music genre), which leads to more engaged learning. When combined with visual representation and the repetition of music, this provides a more memorable learning experience, both for performers and audience members.

The structural aspects of dance provide comfort for students as they build the necessary expertise to innovate. Faber (2016) reviewed the "Isadora Effect," the untested hypothesis that stimulating early motor development via movement practices like dance contribute to more robust neurological and cognitive growth. They declare dance as especially supportive for children under the age of five. (Gregory et al., 2013; Segarra et al., 2018)

Writing in the classroom should promote learning as opposed to solely assessing learning (i.e., "learning to write") (Krom \& Williams, 2011). Creative writing aids in the learning process while building perspective and language dexterity. Poetry, like music, relies heavily on repetition and pattern 
understanding while also remaining conceptual in context. As such, teachers can use poetry to augment both the preliminary and reflection stages of learning. Teachers could employ analogy poetry to introduce new concepts that connect or mirror past information. To have students reflect on their knowledge postlesson, they could write their own poems. Storytelling makes the initial preliminary stage more engaging and memorable while building student understanding of concepts, especially useful for underserved learners. Students telling stories themselves engage their critical thinking, higher-order thinking, communication, creative thinking, practical thinking, knowledge of integration, and ability to explain knowledge without jargon to others. (Gregory et al., 2013; Krom \& Williams, 2011)

Songwriting combines music and poetry, speaking to the concept that complex learning that engages "dual-coding," allowing for long-term retention. Students “discover" music patterns, evoking spatiotemporal reasoning dexterity. They then write and place lyrics that reflect lesson material with matching rhythm over these repetitions, in return promoting a deeper understanding of lesson material. Emotion conveys clearly via both lyrical context and individual music input (i.e., tonal/tempo shifts, note changing, voice and instrument intensity). Consequentially, music may be especially useful for learning about complex concepts like perspectives and the societal context of historical figures. ScreeN.W.riting also succeeds in the conveyance of emotions while also providing room for the same, complicated, expressive contexts of music. It requires physical exertion and fast thinking, making it an attractive replacement for group PowerPoint projects. Instead of group presentations, students could work together to write and perform skits that convey an understanding of lesson material. (Gregory et al., 2013)

Dramatic arts benefit learning by allowing the information to come to life through the acting out of material. Consequentially, they offer a compelling substitute for textbooks, traditionally unengaging and excluding of underserved pupil populations. Theater puts enactment into action by allowing students to act out and improve recall ability relative to reading and writing. Employment of theater in the classroom cuts back on textbook costs, fosters greater scholarly engagement due to its interactive nature, focuses education on the students, and teaches collaboration, communication, and independent thinking. 
Rehearsal builds the foundation for long-term retention, and theater engages and motivates students to rehearse content knowledge. Improvisational theater aids in teaching pupils to think fast on their feet (an essential strength during thesis dissertations), articulate their thoughts more clearly, and integrate scientific concepts into their daily lives. The combinations of play and structure apparent in the dramatic arts are both vital parts of S.T.E.M. experimentation. (Gregory et al., 2013; Segarra et al., 2018)

Previous studies also link art to relief of learning anxiety and frustration in scholars and helping them work through "thinker's block." A study by Kaimal et al. (2016) found creating art relieved stress, improved focus and attention, gave individuals more insight into themselves in adult participants with varying levels of art experience. These findings indicate art incorporation in the classroom may reduce stress and anxiety for pupils with histories of trauma, alternative mental health, or who come from other underserved populations. Art offers space for students to work through obstructions and round out ideas before implementing them; it allows for the working through of mistakes and for sparks of ideas to persist to conceptual completion. Finally, the reflection aspect of art improves impulse control due to the exertion of pausing that allows for the processing of additional information. Reflection makes students aware of their learning process and capabilities. (Segarra et al., 2018; Gregory et al., 2013)

Former President of Rhode Island School of Design (R.I.S.D.) John Maeda often receives credit for the recent boost of interest in S.T.E.A.M.. He takes this concept further by arguing that art provides the space necessary to fully and independently contemplate and test out new ideas: "art makes questions." Questions launch and land discoveries. (Maeda. 2012).

Inquiry solidifies itself as the cornerstone of S.T.E.A.M. learning. It encourages pupils to muse and better frames their understanding of the material. Researchers found that S.T.E.A.M.-based learning enhances students' cognitive learning, especially when stressing learning by inquiry over learning for memorization. It emphasizes the concept that scholars need to learn to think scientifically. In inquirydriven education, teachers leave their roles as all-knowing authority figures and instead take on the role of 
How a Neuroscience Outreach Group Utilizing Art in S.T.E.M. Provides Cost-Effective Strategies in Tackling the United States Education Gap

Grant Howard 16

educational guides. When art and inquiry meet in S.T.E.M. subjects, a balance is struck between critical thinking and hands-on learning within the classroom. (Thuneberg et al., 2018)

Nicole Mace, MEd, states four characteristics as fundamental concerning S.T.E.A.M. learning: reliable teacher support, space for scholars to muse and make creatively, focus on real-life problems, and emphasis on student feedback. Supporting teachers and securing their access to resources guarantees that

they can adequately prioritize pupils and other classroom elements. Large class sizes overwhelm teachers and limit available classroom space. Smaller class sizes safeguard sturdier teacher and student support while providing proper space for thinking and making. Taking real-life issues as opposed to fictional ones empowers students to feel and see how they can use their knowledge to implement real change and progress. Student feedback allows them to feel further emboldened with practice in self-advocacy, often overlooked in traditional classroom settings. It assures the teacher can respond flexibly in adjusting S.T.E.A.M. activities, which may help improve accessibility. Greater visualization usage within the scientific research community may widen accessibility while addressing existing disparities in S.T.E.M. research. Art adds a layer of accessibility to scientific research, both regarding the general lay audience and persons with certain disabilities (i.e., visual impairments, specific learning disorders). (Segarra et al., 2018)

\section{Educational Disparities within the United States}

Educational disparities hold urgency due to prior findings that suggest receiving higher education links positively to several essential aspects of life. These include more informed choices around consumerism, political beliefs, morality and family planning. Receiving a college degree also safeguards the education of an individual's future children and grandchildren, the health of both the individual and their family, and the continuous development of communities. (Ladson-Billings, 2015)

In the United States, disparities based on race, socioeconomic status, and disability status still exist within the education system. Investigators like Gloria Ladson-Billings (2015), argue that our 
education problem's severity warrants recognition beyond an "achievement gap" and instead operates as an "educational debt." Alternatively, with each year that the United States fails to address inequalities, their gravity intensifies. While researchers place an immense focus on determining why these disparities exist, far less research dedicates itself to solutions to address these injustices.

Several factors contribute to and influence an individual's learning process, including their home life, mental health, and access to and involvement with extracurriculars. However, most research focuses on economic-educational disparities and the clash between the American ideals of a strong sense of morality and individualism. Regarding the first, researchers concluded that these economic issues contribute to continual practices of segregation in our school system.

The National Governor's Association claims that the achievement gap remains "a matter of race and class. Across the U.S., a gap in academic achievement persisted between minority and disadvantaged students and their white counterparts.... This is one of the most pressing educational-policy challenges that states currently face." Kozol's (2005) study found differences in spending regarding the amount of capital invested per pupil based on school location. Urban public schools invested far less per pupil compared to suburban schools, which tended to welcome a higher population of white students. (LadsonBillings, 2015)

Ladson-Billings (2015) cites the states of New York, Michigan, Illinois, and California and the urban expanses of Los Angeles, New York City, Chicago, and Philadelphia as amongst the worst regarding segregation for students of color. Los Angeles provides a prime example of a county unable to allocate funds appropriately. Public schools in more affluent, whiter districts received large amounts of both public and private funding and funding opportunities (i.e., film shoots, local business partnerships). In contrast, public schools in less wealthy, more diverse districts received little funding. A case-study on a public school in Compton, Los Angeles, revealed that the school received so little funding that they operated out of years old temporary classrooms. Conditions and structure of these classroom-trailers were poor, with constant termite and maggot infestations and little to no classroom supplies. 
While most fieldwork supporting claims of systematic racism and other social injustices within the education system derive from standardized testing scores, research focused on differential educational areas supports the claim. Educational inequalities affect honors and advanced placement courses and programs, school drop-out rates, and attendance of higher education institutions. Considering these findings, a pivotal area regarding economics and education persists around the amount of time spent in schooling. Empirical data indicates that higher earnings tended to stem from a more significant amount of time spent in schooling. This correlation falls short when accounting for "caretaker" vocations (i.e., teachers, nurses, social care workers) traditionally and predominantly filled by womxn and minorities. For the most part, race, socioeconomic status, and disability status seem to contribute to challenges around succeeding in the realm of higher education and completion of four-year degrees by scholars. (LadsonBillings, 2015; Kozol, 2005)

Another issue facing educational policy and theory revolves around ethical and self-efficacy ideals clashing with one another. Despite our traditional sense of morality and religiosity, the United States also holds strong expectations around personal responsibility. Often, the latter dominates, with selfefficacy outweighing social and community responsibilities. The concept of morals falling to the wayside within the education system holds especially true when deliberating on the experiences of indigenous American populations and the 'Indian Residential Schools.' (Ladson-Billings, 2015; Hanson, 2009)

\section{Educational Outreach Groups}

While many of these disparities call for systematic change, educational outreach groups currently supplement for gaps left by the current system. Taking into consideration the lower rates of S.T.E.M. interest and degree completion within the United States, this holds saliency regarding S.T.E.M. and S.T.E.A.M. outreach. Despite billions of dollars in initiatives aimed at providing S.T.E.M. resources and opportunities to underserved communities by former President Barack Obama, accessibility and funding for S.T.E.M. still meet limitations and continual cuts. Thus, scientific outreach groups play a prime role in 
teaching many of the tools taught through S.T.E.M. that receive little or no emphasis within the publicschool system. The requirement of these skills remains essential in preparing the next generation of scientists so that some of the world's more complicated issues stand a chance of being solved.

Historically, the domain of science engages with communities on multiple levels due to its interdisciplinary nature in terms of practice. Many notable contributions to science spark from the minds of so-called "amateur scientists." Ideally, the interests and needs of the public inform science rather than a limited scientific elite. When this occurs, science carries the profound ability to bridge gaps to unite a variety of people, including scientists, community members, and members from the private sector. Together, these individuals may solve many relevant issues, including those around the environment, mental health, and technology. Thus, engaging in scientific outreach remains vital not only for providing for a better-informed community but also to push the sector forward. (Varner, 2014; Hayward \& Basley, 2014)

Scientific outreach comes in many forms and typically lends itself to two focuses: public participation in scientific research (P.P.S.R.) and public understanding of scientific research (P.U.S.R.). Both practices offer advantages and disadvantages and are easiest to understand in terms of engagement style. P.P.S.R. achieves its purpose through a variety of forms, from survey participation to engaged data collection. It tends to emphasize the active engagement of community members and focuses more on any scientific concerns a community may hold. In return, the chances of the scientific community addressing these concerns receive a boost. P.U.S.R. relies on much more passive community engagement and tends to emphasize the value of community understanding and acceptance of science. Here, community members participate less as potential scientists themselves and more as a "lay audience" engaged by academic scientists with the specific purpose of allowing scientists to expand education and thus acceptance of their specific branch. (Hayward \& Basley, 2014)

More recent efforts push P.U.S.R. to operate in a fashion closer to P.P.S.R. to be more actively engaging. The push is due to the perceived lack of regard for community perspectives and interests as 
well as for legitimacy around scientific research on behalf of academic scientists (i.e., prior reasons for distrust on behalf of underserved populations). The promotion of the philosophy of participatory democracy plays a central role in this regard. Participatory democratic philosophy refers to the theory that research and community engagement ideally influence P.P.S.R. and P.U.S.R.. They, in return, stress the vitality of transparency, integration, deliberation, responsible policy systems, enhancement of community understanding of societal issues, inclusivity of diversity in governance systems, and the acceptance of democratic-making processes. On a national scale, science ideally influences this philosophy in terms of our governance systems. It should consider the broader political system, so research reflects community needs. In order to better avoid the issues that attach themselves to the privilege present in higher academia, dual utilization of P.P.S.R. and P.U.S.R. should occur to provide for the most beneficial, hands-on education experience to community members. (Hayward \& Basley, 2014)

Outreach needs to stray from pop-science practices of heavily relying solely on entertainment. Failure may leave the group vulnerable to harmful propaganda goals (i.e., convincing a community to support your experimentation, talking at local group members as opposed to educating them). Outreach should always strive to inform community members so they can reach their own conclusions. Despite this, the most popular type of outreach activity for S.T.E.M. scholars and professionals to engage in was, by far, presentations (either at the scientists' workplace or away from their workplace) followed by tutoring and judging or organizing a science fair (Andrews et al., 2018).

Scientific outreach goes beyond establishing quality within the fields of S.T.E.M. and providing aid for combatting our educational debt. It benefits all of those involved in the process, from teachers and volunteers to K-12 pupils and community members. Merrit \& Merrit (2017) discovered that working with teachers and supplementing them with resources before the date of outreach positively impacted the actual event. They concluded that outreach, while time-consuming, is vital and worth the required amount of effort for the outcome of success. Outreach inspires and informs teachers of interdisciplinary practices and scientific outreach, something especially beneficial regarding problems of teachers around difficulty 
understanding S.T.E.A.M. procedures in their classrooms. Ergo, a scientific outreach group's ability to address teacher concerns remains fundamental for establishing outreach success beyond the classroom visit. (Perignat \& Katz-Buonincontro, 2019) (Herro \& Quigley, 2017)

Scientific outreach benefits institutions and volunteers themselves, especially graduate scholars involved in research and investigators themselves. The National Science Foundation (N.S.F.) includes a mandatory 'Broader Impacts' section in their grant proposal process. It requires projects to "benefit society and contribute to the achievement of specific desired outcomes" (N.S.F. Grant Proposal Guides, Office of Management and Budget [O.B.M.] Control Number 3145-0058). Scientific outreach focused on presentations in K-12 classrooms offers a way to ensure institutions fulfill civic duties mandated in grant proposals such as the one mentioned. Outreach robustly benefits volunteers individually who are working on theses and more significant projects by allowing them the opportunity to practice communication prowess. Volunteers break down their research to receive real-time feedback while improving K-12 interest in their discipline. (McCann et al., 2015, Andrews et al., 2018)

Scientific outreach extends benefits for S.T.E.M. scholars in deciding which populace to serve. According to Pollock et al. (2017), university students within the S.T.E.M. field who served as peer mentors during educational scientific outreaches in underserved communities tended to return to work with them. Community insight also helps researchers to accordingly set their personal and professional goals and values to suit the collective who they ideally want to serve. Andrews et al. concluded that most scientific outreach participants either felt that outreach met their reality (i.e., outreach is challenging but rewarding) or jumped beyond their expectations.

The top motivating element for participation in outreach stemmed from desires to contribute to the community, improve teaching competence, or for personal enjoyment. All these components contribute to the top method of recruitment: word of mouth. Despite this, many scientific investigators cited seeing no incentive for outreach, perhaps due to lack of money or tenure motivation. This lack of motivation remains an especially fascinating finding as more work comes out on the scientific elite and 
the growing disconnect between members of the general public and the scientific community. Andrews et al. concluded that the top preventatives of outreach participation included lack of time or institutional devaluation of outreach (either by professional mentors or institutions themselves). As such, researchers tended to participate in outreach the least amount of all the S.T.E.M. professionals. (Andrews et al., 2018) Andrews et al. discovered dual benefits of outreach for volunteers and the populations they served. Outreach better connects scientists to concerns of the public which in return better informs science to authentic community issues. Outreach also builds vital trust between community members, especially those with valid reasons for eroded trust, and scientific professionals and scholars. It ensures that K-12 students see a variety of representations and opportunities within the realms of S.T.E.M.. Consequentially, higher recruitment rates should result within a discipline; arguably, quite a few incentives exist for outreach. (Andrews et al., 2018)

More hands-on and interactive outreach styles (i.e., job shadowing, in-class experiments) provide more benefits for students themselves. In one study, K-12 interest in science and scientific careers, as well as interest in independent research outside of the classroom, rose after job shadowing a scientist. (Clark et al., 2016)

Proper representation remains an issue in the disciplines of S.T.E.M.; research indicates that the general public's perception of scientists influences the overall perception of S.T.E.M. itself. Noh \& Choi (1996) noted that pupils' perceptions of scientists as intelligent, hard-working, and inventive, directly opposed their self-perceptions. Despite gender disparities existing within the fields of S.T.E.M., female graduate students generally participated in outreach twice as much as their male counterparts. Such robust representation allows young womxn to see themselves in S.T.E.M.. In an evaluation by Mullett et al. (2013), a word association evaluation administered pre-outreach indicated that many students correlated the word, 'genius,' with the word, 'scientists.' After the outreach visit, 'genius' associated significantly less with 'scientists,' correlating with a $22 \%$ increase in interest in science. This observation provides more insight into why pupils feel disconnected from S.T.E.M., as the general public often views science 
How a Neuroscience Outreach Group Utilizing Art in S.T.E.M. Provides Cost-Effective Strategies in Tackling the United States Education Gap Grant Howard 23

as too difficult or beyond individual capability in classic classroom presentation of S.T.E.M.. The same evaluation by Mullett et al. (2013) used a different technique to evaluate student attitudes towards science before and after the event. The results indicated an almost $30 \%$ increase in female pupils who answered, 'agreed,' as opposed to 'disagree,' or, 'unsure,' to the statement, 'I should like to be a scientist.' Results further support the theory that outreach groups robust in diverse representation, especially when closer in age to K-12 students, play a vital role in building student confidence that they, too, can be scientists. (Andrews et al., 2018)

\section{Evaluation of Outreach Groups}

Considering their crucial role in supplementing the education system, Artful Education founders Emily Gasoi and Sonya Robbins Hoffman (2017) suggest that groups frequently undergo a proper evaluation. According to the National Science Board, evaluation of outreach groups should regard a community's awareness, knowledge, or understanding of; engagement or interest in; attitudes towards; behaviors relating to; and skills based in S.T.E.M. concepts to ensure the vitality of the group's efforts. Outreach groups ideally set out to enhance public understanding and acceptance of science. As such, all parts of the evaluation process should consider changes in knowledge, skills, attitudes, and behaviors of community members. However, the focus should expand further as a smaller scope evaluation fails to consider the learning outcomes of other outreach participants (i.e., teachers, outreach volunteers). (Hayward \& Basley, 2014)

Evaluation typically lends itself to two-time points: before and after outreach engagement. As such, groups should consider evaluation during all stages of a group's growth, from the early stages of development to improve a group's framework. Typically, evaluation criteria reflect these periods by breaking down into two parts: acceptance and process criteria. (Hayward \& Basley, 2014)

Acceptance criteria encompass the evaluation process outreach groups utilize to decide which populaces to serve. During this portion of the process, transparency and representation inform what needs 
attention. Groups with limited resources can decide which communities to engage or maintain relationships through their use. Process criteria refer to the outreach procedures and activities themselves and whether they succeed in fulfilling a group's civic goals. Examples of process criteria commonly accounted for during an evaluation to help a group determine if they reach their ideal impact include costeffectiveness and knowledge assessment. Acceptance criteria serve as part of the evaluation process outside of an outreach event. Process criteria function within the outreach event. (Hayward \& Basley, 2014)

Feedback assures the group adequately hears all those voices involved in the outreach process. A study by Clark et al. finished by stressing the significance of student feedback, specifically when interpersonal in quality rather than knowledge-based. Furthermore, K-12 pupil and teacher feedback safeguard reproducibility both for the outreach group and within the classroom itself. (Hayward \& Basley, 2014; Clark et al., 2016)

Volunteers remain on the frontline of outreach, consequentially obtaining more insight into what works and what needs improvement. They also shape how outreach groups grow, and, as such, their feedback identifies as critical as well. Ann B. Messmore (1997) took note of this when creating a general framework to measure the impact of grassroots-based outreach groups. When forming a specific evaluation plan, groups should consider input from volunteers and resource council members through both individual and focus-group interviews.

Because of the complexity involved during the process of creating an evaluation plan, Gullat \& Jan (2003) suggest ten characteristics for quality assessment of an outreach group's impact: (1) prior standards and goals set forth by the outreach group, (2) community members' personal connection with the group's material, (3) whether or not the groups sets forth role models for the populace to engage and build relationships with, (4) group promotion of teamwork, (5) the continual building of stable relationships between the group and collective members, (6) outreach group intervention during peak points of the performance gap where specifically K-12 pupils often fall behind, (7) the continual re- 
visitation by the group with specific communities to further solidify and strengthen relationships, (8) group ability to further promote teamwork and student understanding of their impact on overall members, (9) group's access to scholarship and other resources for members of the public, and (10) an evaluation plan design to assess and collect data on an outreach group's progress and impact on those served.

While actual appraisal of knowledge behaves as a central focus of evaluation for all outreach groups, this holds especially true for S.T.E.A.M.-based outreach groups due to the application of both art and inquiry. Both art and inquiry assessments tend to lean on the side of subjection. They differ from binary testing in one keyway: they focus on the overall learning process as opposed to just the outcome.

Art evaluation reflects the complex nature of art due to the characteristics of originality and imagination apparent in art as well as the vastness of the field itself, providing for different perspectives around appraisal. As such, it needs approaching with skepticism as well as flexibility. Awareness of institutional goals and values provides for cohesion between teachers of different grades and subject areas. These goals create a proper structure to remain project-specific but flexible, allowing for teacher adjustment and student originality. Appraisal recognizes not only knowledge outcomes but also participant behavior during the building of skills in cognition, creativity, craftsmanship, originality, flexibility, development, self-efficacy, group work, perception, and critical self-assessment. Instead of weaponizing assessment against pupils (i.e., threatening over-talking with grade reduction as opposed to working on behavior), educators should communicate their determination of subject saliency and project failure. (Graham, 2019; The Pew Charitable Trusts, 1995)

Experts within art valuation suggest keeping in mind the values communicated within a piece of work as opposed to the content of knowledge. Responsively, many recommend either using a portfolio or experiment-based assessment process due to the dense rooting in the overall process of a scholarly work. In portfolio work, teachers can flexibly evaluate art characteristics over time and thereby the development of student learning, including around investigation, inquiry, experimentation, innovation, risk-taking, and reflection. Experiments allow for a similar process with an emphasis on group discussion around 
How a Neuroscience Outreach Group Utilizing Art in S.T.E.M. Provides Cost-Effective Strategies in Tackling the United States Education Gap Grant Howard 26

techniques supplemented and utilized during that specific process, outcome product, and reflection. (Winner \& Leekman, 1991/96; Wolf \& Pistone, 1991)

Similarly, inquiry-based evaluation prioritizes the overall learning process as opposed to just the outcome. It also highlights proficiency founded in practical application (i.e., thinking and reasoning, argumentation, communication, modeling, problem posing and solving, use of symbolic, formal, and technical language and operations, use of aids/tools). As such, experts often break down steps within the learning process to match the appraisal of knowledge. The initial evaluation approaches typically root in self-assessment and allow for the tweaking of traditional assessments and transform them into an inquirybased appraisal.

Self-assessment relieves teacher stress by lessening the take-home workload. For example, pupils grading tests with teachers within the classroom cuts back on teacher homework and allows for real-time reflection and information processing. Additionally, it provides teachers with a better idea of initial student retention by allotting pupils to share their content knowledge thus far. This information potentially informs the usage of group activities (i.e., if enough students firmly understand lesson material to lead smaller groups). (Thuneberg et al., 2018; National Resource Council, 2000)

Discovery valuation necessitates measuring actual student development over time, including around initial student interest and knowledge growth. Some examples of questions to ask within this portion include, 'how interested are students initially?,' 'what factors supported or constrained student opportunities for learning?,' and 'how much do they learn and understand in the initial learning process compared to the end?.' Devise assessment accounts for the thinking operations of pupils themselves and how the analysis from prior steps utilize in the planning stage before implementation; helpful questions to ask during this stage include, 'how do students formulate plans to take on problems?,' 'is teamwork involved?,' and, 'how is information from the discovery portion implemented in real-life situations?.' (Pollock et al., 2017) 
Development assessment usually bases itself in reflection around actual implementation and frames either as an out-loud group activity or by each case in the form of self-assessment. Here, students discuss what plans failed and succeeded, challenges met and how students conquered them, and whether pupils worked together. Defense assessment, the last part of inquiry-evaluation, makes available to students the chance to defend their choices and overall work as well as communicate final challenges and successes with the overall class. It facilitates class reflection around deciding what solutions worked best post-activity. In inquiry-assessment, the emphasis on the learning process empowers teachers to respond flexibly. It gives pupils a chance to understand the material fully as opposed to rote memorization.

Scientific outreach group evaluation fills in the more massive gaps left in the education system. As such, outreach groups should stray from traditional practices of prioritizing knowledge-based feedback. Instead, groups should prioritize interpersonal feedback, which ensures groups remain flexible, captivating, thought-provoking, and accessible. Understanding that outreach impacts all involved remains critical, especially for groups large enough for a resource council separate from regular volunteers.

When evaluating for group impact, outreach groups grounded in the arts should formulate an assessment framework founded in quality. A quality-based assessment allows for more objectivity but also more flexibility for pupils to communicate material understanding beyond binary testing options. Another more objective evaluation method to reflect on exists around the quality of inquiry: does an outreach group succeed in challenging the served group to think independently enough to formulate their own research questions?

Deliberating on the anxiety-provoking nature of required assessments, making feedback voluntary may help relieve pressure and anxiety for K-12 students. However, it might potentially skew data if a limited population participate in feedback (i.e., only group members who enjoyed the event respond effectively cutting off feedback from those who experiences differed and may hold insight to improve a group). If assessment stays mainly voluntary, the group should strive for feedback from as many volunteers, students, teachers, and other community members as soon as possible after the event. 
How a Neuroscience Outreach Group Utilizing Art in S.T.E.M. Provides Cost-Effective Strategies in Tackling the United States

Grant Howard 28

\section{N.W. Noggin}

"N.W. Noggin brings together students, scientists, educators, and artists to enthuse and inform academics, primarily K-12, and the public, about science and art. Our participants (who are ALL volunteer) integrate arts to collaboratively develop outreach programs designed to be engaging and personally relevant. We seek to spark a lifelong interest in science and art, provide teaching opportunities, and foster understanding and enthusiasm for ongoing scientific research and art in our community" (N.W. Noggin Mission Statement).

Northwest (N.W.) Noggin (Northwest Neuroscience Outreach: Growing in Networks) is a S.T.E.A.M.-based neuroscience outreach group located in the Pacific Northwest started by Neuroscience educator Bill Griesar and artist and educator Jeff Leake. Volunteers ultimately drive this grassroots operation; scientists and artists in all stages of their careers and lives come together to contribute to an engaging learning experience from combining their expertise. N.W. Noggin gathers brilliant minds of a variety of disciplines to discuss neuroscience research, make art, and connect with communities.

N.W. Noggin believes in community-led education where K-12 scholars feel empowered by knowledge as opposed to fearful of it. The group aims to reach underserved communities and learners who do not receive the same opportunities that others in wealthier districts may have. As such, N.W. Noggin goes to where the people are as opposed to bringing students to the group, keeping the power in the hands of the community while maintaining comfort and accessibility for all learners. K-12 scholars set the pace and steer the direction of the visit by sharing what they already know and what they want to know. Furthermore, while typical outreach activities exist and participation is encouraged, volunteers never require students to engage. Students may learn on their own or in groups. This option is critical for reaching underserved learners who may perform better academically when presented with relational and real-life incentives. Instead, they decide which activities to partake in and volunteers to talk to: they choose their educational journeys when interacting with N.W. Noggin. As such, N.W. Noggin responds 
How a Neuroscience Outreach Group Utilizing Art in S.T.E.M. Provides Cost-Effective Strategies in Tackling the United States Education Gap Grant Howard 29

flexibly, permitting outreach to remain a unique experience that flexes to meet unique community needs each visit.

While not research-specific, N.W. Noggin shares information on research and very much incorporates public engagement into every aspect of the outreach. Many volunteers work or intern as researchers around the Pacific Northwest; N.W. Noggin builds a paramount bridge between researchers, clinicians, students, and communities so that scientific information reaches those whom it impacts most. N.W. Noggin heavily incorporates interdisciplinary learning into its practices to provide an intriguing case of S.T.E.A.M. succeeding in real-time. Pupils light up when interacting with N.W. Noggin due to the engaging and unique experience and opportunities to self-express while gaining new knowledge. N.W. Noggin spends time not just dedicated to memorizing new concepts but actually putting those concepts into action to gain first-hand experience.

N.W. Noggin never exploits hard knowledge assessments that may provoke anxiety in students, and consequentially take away from their learning experiences. Just as the group never forces participation, N.W. Noggin keeps content-retention evaluation minimal to ensure pupils continue to feel empowered by learning as opposed to oppressed by it. However, the interdisciplinary nature of N.W. Noggin activities allows for a unique alternative route to assessing the group's success in fulfilling its mission statement. Art produced during outreach efficiently serve as points of assessment considering portfolio evaluations. To ensure students get to keep their work, photograph documentation enables masterpieces and their messages to stay, if wanted, with their creators. Photography, if deployed often in outreach to document community engagement and experiences, may serve as a keyway for N.W. Noggin to evaluate their work: do pupils enjoy themselves within the learning process when they think nobody is looking?

Additionally, teacher feedback serves as an essential area for assessment of N.W. Noggin. Frequently, teachers share their experiences via blog posts and provide insight into whether outreach tactics continue to work beyond the classroom visit, especially in underserved learning populations. North 
Middle School in Grants Pass, Oregon, often engages in student inquiry sessions before annual visits. Communities visited multiple times might build these practices up to see how student inquiry evolves with each N.W. Noggin visit. The nature of the inquiry-based evaluation provides for an assessment of critical thinking as opposed to memory. Potential assessment factors include question complexity (i.e., do inquiries remain focused on brain myths and basics or do they evolve conceptually with each visit?), innovation (i.e., does the inquiry focus on ideas or concepts yet to be considered?), and commonplace (i.e., how many students asked this question?). These considerations would provide N.W. Noggin insight into the effectiveness of more conceptual goals that may prove harder to measure. (Endicott \& Griesar, 2019; Griesar, 2020)

N.W. Noggin often employs the following activities that hold potential for both evaluation and teacher independence. The content after focuses on benefits for volunteers who, while not the main focus of assessment, should be considered during the evaluation process.

\section{S.T.E.M. Activities}

Some of N.W. Noggin's activities center solely in S.T.E.M. as opposed to S.T.E.A.M.. They may provoke interest in S.T.E.M. careers as opposed to S.T.E.M. in the classroom due to their hands-on and engaging nature. These activities tend to provide real-life experiences that provide students insight into the engrossing qualities of S.T.E.M., while deepening student understanding of gross neuroanatomy. "3DBrains," "Hold a Brain," "Animal Brains," and the "Sheep Brain Dissection" all offer students a unique opportunity to sharpen understanding of different lobes held in their hands. Often, perception shifts and conceptual connections click during these activities, something critical that remains missing from traditional learning environments. The very nature of holding and observing actual brains remains unique and memorable, providing for long-term retention beyond the classroom.

Unlike S.T.E.M. in the traditional classroom, art and inquiry are encouraged, and pressure never placed on student ability in rote memorization. S.T.E.M. activities provided by N.W. Noggin offer a 
unique opportunity to try out different S.T.E.M. techniques while improving research, data analysis, and critical thinking skills. Observation and reflection, fundamental parts of these activities, feed into these skills. They are immensely valuable in rehearsing impulse control. If a scientist rushes through an experiment, what might they miss from not taking in both external and internal factors influencing parts of their experiment or inquiry journey?

N.W. Noggin's S.T.E.M. activities provide an opportunity to try out research skills and procedures neuroscientists also apply in some of their own work. Some analyze brain specimens carefully to keep them intact. Others take the organ apart to study the inner workings like a mechanic might a car. Still, some researchers grind up the brain to examine aspects of fine neuroanatomy. Dissections and specimen observations allow for direct, memorable exploration of neuroanatomy, and structure and function relationships that, when paired with reflection, critical thinking, and problem-solving skills, can connect to real-life experiences. Reflection involves an inward analysis of observations of the self. Framing data analysis in a more personally relatable manner allows students to see how the skill plays in their lives and Noggin activities. Do animal brains differ structurally? What structures revealed in the sheep dissection span across many species? Why might electrophysiological activities cause a shocking feeling?

These activities empower students by reminding them of the discovery process, including their own questions and explorations. Traditional classrooms often treat questions as worthless distractions instead of as important starting points in any scientific encounter, particularly if teaching to a standardized test. N.W. Noggin, in contrast, encourages student questions and values student insights and perspectives wherever possible.

Not all the S.T.E.M. activities can be altered as easily as S.T.E.A.M. activities for non-S.T.E.M. subjects or student rehearsal outside of the classroom. They typically require the purchase of equipment, and some like the "Human to Human Interface" (from Backyard Brains) and "Mindflex" can apply to other subject fields with tweaking or "hacking." This cross-application leaves room for student innovation 
and creativity. Can a student succeed in finding a way to use N.W. Noggin technology in a new and exciting way? Even better, could teams of pupils innovate jointly? S.T.E.M. heavily emphasizes teamwork every step of the way, whether brainstorming or proofreading scientific manuscripts.

All pupils participate in these S.T.E.M. activities as they are accessible to most students and help provide a sense that anyone can succeed in the realm of S.T.E.M. if they choose. No barriers to science exist based on ability, race, gender, or socioeconomic status; discovery and inquiry stay open to all. Unfortunately, teacher accessibility may be more limited due to the nature of obtaining the biological specimen. However, an array of brain models exists online, and teachers can recreate the "Sheep Brain Dissection" without N.W. Noggin if the classroom budget allows. N.W. Noggin provides online resources to expand neuroscience involvement beyond the visit.

Photography offers an alternative assessment method for student engagement in S.T.E.M. activities. Do students appear to enjoy themselves? This can be followed up with inquiry-based assessment: did S.T.E.M. activities influence student knowledge enough to alter the quality of inquiry?

\section{D-Brains and Introduction}

The start of a N.W. Noggin outreach visit tends to lead with an introduction, both to their mission and members. This introduction, of course, includes neuroscience-in the form of 3D-printed brains! Faces light up as Dr. Griesar's words around neuroanatomy and functions come alive in his hands. An array of PLA-printed brains in a variety of colors, including a rainbow brain, a brain encased in an etched wood shell, and a few brains based on Dr. Griesar's own noggin often star in outreach. He, Jeff and student volunteers introduce brain lobes, spinning the brains so students can see exactly where the focus is. Sometimes, additional brains end up amongst the eager hands of a captivated audience, so they can follow along by handling brains in real-time. Other times, after Dr. Griesar asks if students know about different cerebral lobes, or other aspects of brain structure and function, hands begin flying all around the noggin area as pupils excitedly explain their own understanding of neuroscience. The 3D-brains always remain 
out through the entire outreach. Even if students do not initially get a chance to see them during the introduction, an opportunity always exists for everyone to have a turn studying them hands-on.

The outreach opening includes the volunteer introduction, in which graduates and undergraduates share information about themselves, including their interests, motivations, and arts and research experience and expertise. Volunteer proficiency varies, from speech pathology and researchers of neurodegenerative disorders to metal sculptors and musicians. They shape everyone's overall experience and bring the group to another level of inclusivity. When volunteer backgrounds are made known, students can better direct their inquiries during the student-led Question and Answer (Q\&A) portion of the introduction. This Q\&A ensures that K-12 scholars share their expertise and their focus on their actual interests. When the group breaks for activities, they can always find the volunteer they wanted to talk with for a more one-on-one discussion.

The introduction varies in time based on the number of students and volunteers and the time made available for the outreach. The Q\&A reflects this; sometimes, in-depth discussions around specific topics in neuroscience last a half-hour while, other times, only ten minutes are available for questions before the group must break out into activities. N.W. Noggin ensures a flexible structure to accommodate specific school needs. Despite possible time crunches, student questions never remain unanswered. Even if the question cannot get answered during the outreach visit itself, Dr.Griesar and many Noggin volunteers always answers questions via an informative, easy-to-read blog post about the experience (N.W.noggin.org).

Plus, the 3D-brain introduces an exciting technology: 3-Dimensional printing. Many pupils are inspired by these models, and start dreaming up other potential ways to harness technology to innovate in other disciplines. The 3D-brains also provide an alternative for students who may feel less comfortable holding or touching actual human brains. Pupils discover for themselves the differences in human brains based on age by comparing the 3D-printed brain of an adolescent to that of adult brains. A 3D-printed skull with a "stake" through the skull and a plastic brain inside inform pupils of famous neurology patient 
How a Neuroscience Outreach Group Utilizing Art in S.T.E.M. Provides Cost-Effective Strategies in Tackling the United States Education Gap

Grant Howard 34

Phineas Gage. This railroad worker survived trauma in the frontal lobe yet shortly after began experiencing negative personality traits (i.e., became disagreeable, cranky). Gage provides an early case study of the effects of physical brain trauma, and the relationship between brain structure, function, and behavior.

\section{"Hold a Brain"}

The "Hold a Brain" activity persists as one of N.W. Noggin's most memorable learning experiences. Students and community members hold and touch real human brains during the outreach to gain insight and powerful perspective regarding their own brains. N.W. Noggin has been the recipient of brain donations from BioGift, an organ receiving concern based in Portland, Oregon. One of their most prized specimens includes a brain pumped full of red and blue acrylic paint. The paint emphasizes vein and artery pathways, meant for educating medical students learning surgery. However, K-12 students also appreciate the bright colors and blood flow pathways as they often make learning more accessible, compelling and intriguing! Brains make messes and harsh chemicals preserve them. As such, N.W. Noggin requires gloves when interacting with the brains for safety's sake. The gloves do not hinder the hands-on learning experience; however, K-12 scholars still gain a new perspective on the fragility of our brains! The acrylic-pumped brain still has its dura mater intact, providing a unique opportunity to compare the two textures: which one feels "tougher"? Holding real brains extends an opportunity for pupils to understand better how brain trauma happens in popular sports and vehicular accidents. This know-how provides insight into the importance of safety precautions (i.e., helmets, seatbelts) while equipping them with needed proficiency for facing real-life situations. (Griesar, 2020)

"Hold a Brain" offers other perceptual shifts for students. The entirety of an individual's perceptions, personality and experiences exist within the brain. Holding a brain is like holding an entire life or, for those with more spiritual beliefs, a soul. Pupils remember this as volunteers encourage gentle touches and pull the focus to the delicate nature of the brains during interactions with them. How would a 
student want someone holding their own brain to treat it? "Hold a Brain" imparts a powerful lesson in empathy that allows K-12 students to rehearse walking in someone else's shoes. It also reminds them of a powerful, unifying biology within both human species and the animal kingdom: the brain.

\section{“Animal Brains"}

The animal brains proffer an intriguing alternative for students weary of the human brains and substantial supplementary aids for those who do want to hold the brain. A variety of brains and eyeballs, from different species, including raccoons, rats, pigs, cats, and cougars, are displayed in sealed jars. Artist and Portland State alumni Darrin Lane even preserved a bear brain and a few human brain slices in plexiglass as educational art. These slices also render a physical example of just what the anatomical directional terms "sagittal" and "coronal" actually mean. (Lane \& Griesar, 2019)

Students drive the focus of the activity, with volunteers encouraging inquiry and reflections of their real-life experiences. Frequently, pupils from more rural areas connect to the brains of farm animals, with many able to connect behavior from the animals they interact with daily to what they are learning in the classroom. In contrast, students from urban or suburban areas tend to make those same connections with brains of household pets or city-dwelling creatures. Pupils reflect with volunteers on why animal behavior may differ based on differing neuroanatomy (i.e., if one species is social and another solitary, would one observe differences in specific brain structures?). The activity aims to deepen pupil understanding of gross neuroanatomy while practicing comparison skills commonly employed in research.

\section{"Sheep Brain Dissection"}

Dissecting a sheep brain compels K-12 scholars to learn about the brain enjoyably while practicing important S.T.E.M. skills. Many researchers dissect as part of their lab work, and not all pupils explore neuroanatomy during their primary education. The "Sheep Brain Dissection" presents pupils with a taste of everyday work life for some neuroscientists and researchers. 
Identifying brain structure during the actual dissection may help with long-term retention of gross neuroanatomy. The unique and hands-on nature of dissection inevitably makes the learning experience more memorable. Instead of providing a looming list of questions that may pressure, disengage, or cause anxiety in students, volunteers ask knowledge-based and conceptual questions throughout the process. The "Sheep Brain Dissection" intends to deepen student understanding of the actual methodology and grant them moments to pause and reflect actively during the learning process as opposed to rushing through to the end. Emphasis on reflection helps remind pupils that every step of the learning process is essential: not just one question on a standardized multiple-choice test. Questions and prompts include, "can you think of one animal that does not have sulci and gyri?," "what type of matter (grey or white) is the corpus callosum made of? what does the corpus callosum do?," "what lobe is this and can you name one network that this lobe participates in?" and, "name one function of the amygdala." (Griesar, 2015).

Pupils work in pairs or small groups during the "Sheep Brain Dissection," building dexterity founded in teamwork and collaboration. Much of S.T.E.M. and related vocations rely on these capabilities and understanding how to work effectively with others. Discovery and innovation often progress through group collaboration, and teamwork also allows for greater accessibility. If a student feels uncomfortable with an aspect of dissection, their team may work together to organize accommodations so that everyone can partake in some form while safeguarding enjoyment of the learning experience.

Teachers can efficiently conduct sheep brain dissections of their own by making a few one-time purchases of dissection tools (i.e., wax dissection trays, goggles, dissection tools). One may purchase sheep brains and vinyl gloves for a reasonable price, making it a fun experiment for teachers to repeat each year with a new class.

\section{S.T.E.A.M. Activities}

Many of N.W. Noggin's activities focus on deepening student understanding of neuroscience concepts through creating a physical representation of brain structures. These activities result in 
representative products, either two-dimensional or three-dimensional in quality. Final products of S.T.E.A.M. activities successfully convey student understanding of the presented material, useful for assessment of retention of knowledge, while also building up student expertise. The projects are handson, making them extremely accessible to more pupils while permitting direct engagement, personal relevance, and the chance to relieve stress and tension through the making of art. Even the rowdiest of students tends calm during at least one of these activities, if not more. Furthermore, the artistic aspect makes room for including students with a history of trauma or neurodevelopmental disorders. Where words so often fail, art often speaks volumes.

Having a physical representation also grants students a reference point to enjoy and revisit beyond the lesson. The arts allow room for innovation and, thus, unique learning experiences despite the repetitiveness of information. Building a series of pipe cleaner neurons in an array of colors or different forms intrigues pupils much more than filling out worksheets or reading textbook segments repeatedly. Artistic representations transform seemingly dry concepts into the fun challenges they exist as in the real world. N.W. Noggin's representative S.T.E.A.M. activities allow neuroscience to properly spring to life through art right in front of the students' eyes.

These activities offer another essential benefit: creativity. Creativity, as touched upon, combines expertise with self-expression and propels innovation forward. These activities endorse thinking "outside the box" and trust in their own intuition and thought processes. Too often, schools encourage conformity, apparent in standardized testing methods. N.W. Noggin equips pupils with outlets for self-expression and ways to feel empowered through their learning process. N.W. Noggin sponsors S.T.E.A.M. activities with these goals in mind that provide some of the most potent tools: information on the organ that impacts every aspect of their daily lives.

Arts require observation to detail, a critical component of research. Scientists need to pay attention to every detail when analyzing their data, including the procedure of data collection. N.W. Noggin's S.T.E.A.M. activities create a fun and open space for students to rehearse related research and 
How a Neuroscience Outreach Group Utilizing Art in S.T.E.M. Provides Cost-Effective Strategies in Tackling the United States Education Gap Grant Howard 38

data analysis dexterity. Students need awareness of detail to succeed in fulfilling many of the activity goals. Often, N.W. Noggin presents multiple goals in its S.T.E.A.M.-based activities to promote multifaceted learning. As the brain "dual-codes" art, N.W. Noggin encompasses neuroscience through art to jointly ensure long-term content-knowledge retention and exposure to various artistic techniques.

Students successfully convey their understanding of concepts through more than language alone. Arts can enable emotional expression and the release of frustration, critical for trauma-aware and accessible classrooms. Students practice reflection skills while remaining actively engaged in the activity, expanding reflection beyond its traditional classroom reputation of a silent and still activity. This inclusion creates room for learners with abundant energy or intense anxiety, many of whom struggle with sitting still in traditional classrooms due to racing thoughts and trouble with emotional regulation. As art engages multiple neural networks, S.T.E.A.M.-based reflection better supports their engagement, inclusion and learning about the brain and behavior.

Arts rely on an understanding of structure to build pieces that either playoff or purposely break accepted patterns. Even artistic rebellion requires a degree of understanding of systems in a particular art form to break the rules to create a piece whose message provokes. N.W. Noggin makes clear the structure and guidelines of the arts while also encouraging students to jump off and try out original techniques and ideas wherever possible. Thus, the structure serves as a reference and point of comfort until learners build the expertise necessary to innovate. So long as a physical representation of the neuroscience subject manifests as a result, all of these art processes are helping for learning more.

These activities prevail as extremely accessible to teachers due to their low cost or utilization of everyday classroom materials. N.W. Noggin provides online resources for all these activities with clear instructions and supplementary information. These activities are perfect for teachers wanting to expand the outreach experience beyond the outreach visit and into their everyday classrooms. The nonlinguisticbased nature of art activities makes them especially pertinent to underserved learners, another consideration for teachers with larger populations of these students. The interdisciplinary nature makes 
these activities very easy to alter to fit different lessons while remaining accessible. Projects like those described easily replace solitary assignments and evaluations for teachers hoping to avoid standardized testing where that is allowed.

Assessment for these outreach projects may be based on a portfolio that students create. Teachers can apply critiques of complexity, originality, and interpretation with an added consideration of conveyed messages (i.e., content-knowledge) to evaluated S.T.E.A.M.-based activities to assess student knowledgeretention. While post-visit assessment cuts off K-12 ability to "defend" work, N.W. Noggin could work around this to determine success in student conveyance of knowledge. Various volunteers might involve themselves in assessing a final product to allow for a more robust knowledge valuation. Photography ensures that the art remains with student creators yet enables N.W. Noggin to assess it after outreach. Perhaps for each outreach visit, an individual volunteer might take responsibility for documenting all art or as much art as possible. Later, the volunteers could assess the work.

\section{"N.W. Noggin Brain Map"}

N.W. Noggin's Brain Map project prompts students to consider their brains and capabilities, engaging in critical thinking, reflection, and self-awareness prowess. It offers pupils an idea of how much their brain impacts their daily lives as they must consider the roles their brain plays in everyday activities. Students work together or brainstorm on their own to answer, "how would you explain what networks of neurons in this brain help you do-through a picture?" (Griesar, 2018). Many public schools are equipped with big, colorful craft paper rolls, so volunteers can create a giant paper representation of the brain on the floor, with colors varying by lobe. Innovation, creativity, flexibility, and capability shine through during this activity as students work together on a piece of art. As they draw out the various perceptual, cognitive and behavioral functions associated with neural networks in each brain area, they simultaneously deepen their understanding of neural functions and gross neuroanatomy. The brain map focuses on helping pupils 
How a Neuroscience Outreach Group Utilizing Art in S.T.E.M. Provides Cost-Effective Strategies in Tackling the United States

Education Gap

Grant Howard 40

draw connections between brain functions and interactions with the surrounding world. (Miyamato, Leake, \& Griesar, 2016; Shaw \& Griesar, 2018)

An assessment might focus on analyzing this activity’s final map for overall group understanding of neuroscience. Photography of the art would allow for closer inspection later without taking the work away from the class. Similarly, this activity could be easily reworked for an individual project and, thus, assessment of individual understanding by using construction paper and creating smaller brains.

\section{"Pipe Cleaner Neurons"}

One of the most popular N.W. Noggin activities involves building a neuron or glial cell out of pipe cleaners. The pipe cleaner brain cell provides a hands-on way of deepening understanding of fine neuroanatomy and neural functions while creating a physical representation of a neuron or glial cell to keep and share. The activity involves an introduction, along with examples of neurons themselves. Because our brains hold multitudes of neurons and glia, students can choose from a variety to learn about and focus on in their art. This activity affords pupils the freedom to expand beyond a "classical" neuron to try making other brain cells (i.e., retinal cone photoreceptors, rod cells, auditory or vestibular hair cells, cerebellar Purkinje cells). (Miyamato, Leake, \& Griesar, 2016; Griesar, 2018; Griesar, 2018)

The primary pipe cleaner neuron is easy and fun to make. Volunteers use accessible analogies throughout the creation process to make following along even for the youngest of neuroscientists easy. As each part of the neuron pieces together, volunteers learn what students already know and fill them in on the basics of what they might not know yet. The freeform quality of the activity also allows students to ask volunteers their own questions in a more one-on-one setting. Inquiry again puts control of learning back into pupils' hands.

The simplicity of the pipe cleaner neurons means building expertise in this craft and the related material more swiftly, allowing room for pupils to innovate and make innovative creative choices. The pipe cleaner neuron offers much to individualize, from neuron type to color to size to creation techniques. 
How a Neuroscience Outreach Group Utilizing Art in S.T.E.M. Provides Cost-Effective Strategies in Tackling the United States Education Gap Grant Howard 41

For example, instead of twisting pipe cleaners together to form an axon, an individual might braid them together, creating a different aesthetic and a flatter axon build. Alternatively, one could use sparkly pipe cleaners to represent the myelin sheath, or the nodes of Ranvier, or whatever part of the neuron the student wants to emphasize. There is plenty of room for self-expression and innovation with this activity.

\section{"Plaster Brains"}

The "Plaster Brain" project focuses on deepening understanding of gross neuroanatomy while enabling pupils the chance to try out a new art form. Students mix plaster before pouring the liquid base into a brain-shaped mold; once the plaster solidifies, they can then paint on different lobes and brain areas. Pupils apply their learned content-knowledge to create a labeled brain that they can take home and share. This keepsake encourages students in neuroscience outside of the classroom while also providing them the chance to be teachers themselves to family members and friends. (Miyamato, Leake, \& Griesar, 2016; Shaw \& Griesar, 2018)

Most students can participate in the "Plaster Brain" activity, and plenty of room exists for emotional release as well as thinking and making. Buying plastic brain molds and plaster online, if a classroom budget exists, allows teachers to effectively conduct this project without N.W. Noggin present. Detailed instructions remain open access online for consultation's sake. Small tweaks to the lesson enable the activity to apply to other subjects. The activity shifts perception and reveals cross-subject connections by opening a discussion as to what brain functions might play a role during different activities and skill use (i.e., reading, writing, research).

\section{"Clay Brain"}

The "Clay Brain" activity is a faster, more hands-on version of the "Plaster Brain." Students use their hands to mold air dry clay into a brain instead of pouring the plaster into a premade mold. Students start by rolling a little less than a handful of clay into a small ball. Next, they press down to flatten the clay before using their fingernail to indent the middle, creating the corpus callosum. Then, students take 
How a Neuroscience Outreach Group Utilizing Art in S.T.E.M. Provides Cost-Effective Strategies in Tackling the United States Education Gap Grant Howard 42

smaller amounts of clay to create the brain stem and cerebellum. To create texture in the cerebellum and neocortex regions, pupils roll a separate piece of clay into snakes before folding them over the created brain. Alternatively, they can use their fingernails or pipe cleaners to create the grooves and hills of the sulci and gyri. Let the brains dry and paint on the brain regions! (Griesar et al., 2019)

Like the "Plaster Brain," the "Clay Brain" deepens student understanding of neuroanatomy through art. The act of physically making and shaping the brain allows for emotion release as well as the opportunity to work through learning frustrations and mistakes. For underserved learners who retain more by experience, the act of forming different gross brain structures may be more memorable and enjoyable than traditional lectures. Anyone can easily involve themselves in this activity.

\section{"Found Neuron Project"}

The "Found Neuron Project" builds upon some of the other S.T.E.A.M.-based activities (i.e., "Neuron Gelatin Print," "Draw a Neuron"). The activity likens to a version of "I Spy" with a specific goal: finding neurons in and making neurons out of items available in your own environment. The activity aims to deepen pupil understanding of fine neuroanatomy while revealing the unity present across different natural systems. The conceptual aspects prompt students to pause and reflect on their worlds to "connect dots" between seemingly unrelated subject matters. Learners must shift perspective and think abstractly to discover forms in nature and innovate based on them in real-time. (Miyamato, Leake, \& Griesar, 2016)

Requiring no specific supplies makes this activity extremely accessible: just bring your imagination and an eye for neurons! Teachers and students may participate in this activity without N.W. Noggin, both in and out the classroom. N.W. Noggin suggests the following for consideration: "Take a look around you; what things do you see that share the structure of a neuron? Can you construct a neuron out of things you find? What things for you represent the function of a neuron? Or the functions of a specific part of neurons? Do those things have personal meaning or say something about you? Beyond the 
How a Neuroscience Outreach Group Utilizing Art in S.T.E.M. Provides Cost-Effective Strategies in Tackling the United States Education Gap Grant Howard 43

basic structures, are there more features of a neuron that you can identify in your found neuron?" (Griesar, 2020).

Putting them down on paper or via photography makes found neurons into informative, sharable, lasting art pieces. The images also reveal something about the nature of the artist behind the work. For example, students fascinated by flora may find themselves drawn to flowers and other plant materials. In contrast, others passionate about environmental issues may put various plastics and humanmade materials together for a second life.

\section{"Neuron Gelatin Print"}

Building off the "Found Neuron Project," the "Neuron Gelatin Print" activity allows students to create physical representations of neurons sans photography. They can also create new cells based on different natural and classroom supplies using paint, paper, and a gel slab. The project begins with a discussion around the different types of brain cells and their functions and why some plants may have similar forms to neurons and glia. These cross-connections permit pupils to reflect on their expertise in the surrounding world and put knowledge into action. It challenges learners to innovate and think creatively to form an image of a neuron. The work should succeed in representing the depth of a student's understanding enough for others to understand the information present in their art. The flexibility and space apparent for "thinking and making" lets students think outside of the box to express themselves and understand lesson materials more deeply. (Miyamato, Leake, \& Griesar, 2016)

The dual lesson also enables pupils to experience printmaking, an art form not always available in K-12 schools. This dexterity can transfer to fashion via a clothes-based printing process to endorse student self-expression in other areas of their lives. It also transfers to other subjects by alteration of the image goal to that of any additional desired focus. The art materials are easily found, and the gel slabs may be re-used for an extended period. Printmaking is a hands-on activity that many students might not get the chance to participate in otherwise, making the experience more memorable. 
How a Neuroscience Outreach Group Utilizing Art in S.T.E.M. Provides Cost-Effective Strategies in Tackling the United States Education Gap Grant Howard 44

Pupils produce a final, physical work to show off their expertise while allowing for a way to evaluate content knowledge without standardized testing. Photographs could document each piece for subjective evaluation to help with assessment and display.

\section{"Draw a Neuron”}

The "Draw a Neuron" project also builds off of the "Found Neuron Project." It relies on learner expertise of fine neuroanatomy to allow them to visually represent a neuron by hand. Contrasting to the "Neuron Gelatin Print" activity, "Draw a Neuron" focuses on students using their observation prowess to capture details of their found or imagined neurons, innovating in real-time as they do so. Flowers, cars, animals, or anything else in a student's imagination can make up drawn representations of cells, leaving plenty of room for self-expression and self-awareness. The quiet aspect of drawing creates space for individual reflection on content while releasing emotion and building dexterity. Drawing styles differ vastly depending on the pupil and their experiences, allowing individual interpretations to shine through. This allowance for individual style can be especially helpful for learners shifting perception during group reflections. They might prompt learners to consider alternative viewpoints from their own, expanding their own world views and approaches. "Draw a Neuron" only requires paper and drawing materials, making teacher replication and student rehearsal outside of the classroom simple. The nonverbal aspect of art also encourages underserved learners to feel more comfortable and capable in science. (Miyamato, Leake, \& Griesar, 2016; Rosen, 2013)

\section{"After Image Painting"}

The "After Image Painting" activity focuses on two goals: one S.T.E.M.-specific and the other art specific. The first centers in deepening the understanding of the visual system and related neurons: "know the basics of color perception" and "understand how fatigue in the visual system causes after images" (Griesar \& Leake, 2014). The second goal: "understand the color wheel and after images" (Griesar \& Leake, 2014). To achieve these goals, learners use their base expertise to problem-solve, creating an 
alternative image. They need to use colors that contrast the actual colors the artist hopes for the viewer to see in the after-image, which may require some trial and error. The simplicity of the required supplies and online resources available make it an excellent project for teachers to use outside of the outreach visit. Plus, group evaluation can be fun and informative! Students test out each other's prints to see if their peers succeed and utilize critical thinking skills if they do not: does a solution exist to the problem?

\section{"Zoom Sequence”}

The "Zoom Sequence" activity challenges pupils to wield their expertise in neural communication patterns and action potentials. The activity intends for learners to properly order the sequence, as demonstrated within the structure of a neuron. Students each obtain an image to represent a part of a neuron's communication sequence. They must work with one another to find the correct order to cause the neuron to "fire" a message. The collaborative nature allows students real-life practice in teamwork and verbal communication. Volunteers ask a series of conceptual questions to prompt learners to use their critical thinking and problem-solving capacity. For example, "would changing structure change possible neural function?," and, "Why would a series not in order not function?" (Griesar \& Leake, 2014)

Like the "Found Neuron" activity, the "Zoom Sequence" activity provides pupils with space to reflect on their experience of natural systems and the collaborative unity within these systems required for proper functioning. How might social and humanmade systems abide by similar structural and functional requirements, and does room for flexible responding exist in these structures? The connection between differing systems leaves plenty of room for innovation and self-expression. Students can create their own "Zoom Sequence" based on other systems to "think and make" while also rehearsing material knowledge. Plus, the assessment is straightforward: do these systems succeed in firing? Find the original, free resource online to conduct this activity at home without a hitch. (Griesar \& Leake, 2014) 
How a Neuroscience Outreach Group Utilizing Art in S.T.E.M. Provides Cost-Effective Strategies in Tackling the United States Education Gap

Grant Howard 46

"Arpillieras"

N.W. Noggin recently teamed up with p:ear and Chilean artist and educator Cecilia Araneda to make "arpilleras," powerful stitched fabric depictions of traumatic experience that offer opportunities for emotional expression and memory. These arpilleras can be adapted to show structural forms, or express aspects of brain function. For example, beautiful representations of different neurological functions and neuroanatomy can come to life as bright fabric forms. The activity requires some patience and reflection but leaves ample room for self-expression and innovation. Teachers might replicate this activity by using felt and either teaching simple sewing skills to learners or employing fabric glue. A paper-based collage presents an alternative activity with similar benefits and a more straightforward supply list. It efficiently alters to fit other subject matters as well. (Griesar \& Leake, 2020)

\section{Technology-Based Activities}

The final set of N.W. Noggin activities focus on technology. Some offer differing perception, like the "Drunk Goggles"; while others offer insight into technology frequently used in neuroscience research, like the "Human to Human Interface" from Backyard Brains. "The Human to Human Interface" and "Mindflex" (the latter from Mattel) both provide students with examples of the power of the brain and the electrical nature of neuron communication. Because of the equipment cost, accessibility for these activities is more limited compared to the S.T.E.A.M.-based activities; however, they offer valuable insight into how brains work in the real world. Technology continues to grow in tandem with neuroscience. As such, students can learn a great deal experimenting with this relatively low-cost electrophysiological equipment.

If a classroom budget exists, classroom accessibility without N.W. Noggin may be higher than some of the S.T.E.M. activities requiring more sensitive biological specimen. Lower utilization of free or existing classroom materials means that a classroom budget will likely need to account for expenses. Some expenses are one-time, like electrophysiological equipment or the items themselves in the case of 
How a Neuroscience Outreach Group Utilizing Art in S.T.E.M. Provides Cost-Effective Strategies in Tackling the United States Education Gap Grant Howard 47

the "Mindflex" game and the "Drunk Goggles." Keeping supplies to repeat with different classes is easy once the classroom investment has been made.

\section{"Mindflex"}

The "Mindflex," a headset-based game from Mattel, "reads your brain waves" via EEG sensors to levitate a ball over the game console. Players must concentrate on lowering and raising the ball through obstacle courses or against another player. It provides learners the chance to experience the power of their minds and practice patience. "Mindflex" tends to make appearance mainly in big public outreach events like brain fairs. However, teachers with classroom budgets could purchase this for years of use or student innovation. For example, musicians have created "brain music" using the "Mindflex." Singer-guitarist Robert Schneider of 'The Apples in Stereo' shared with 'Wired' that 'it's kind of Punk rock: you can hack the "Mindflex" yourself and make brain music" (Thill, 2010). While the music may not be completely melodious, it is a fantastic way for students to try out technology innovation. The "Mindflex" supplies students with hands-on experience that they can innovate to make "brain music." The skills involved might transfer to other practices, like meditation or body checks, often helpful in emotional regulation and self-awareness. (Griesar, 2015; Thill, 2010)

\section{"Human to Human Interface"}

The "Human to Human Interface" combines a piece of electromyography (EMG) equipment and a TENS unit to connect to an individual's peripheral nervous system (PNS) via electrodes placed atop the flexor carpi ulnaris muscle near the elbow by the ulnar nerve. If two people hook up to the equipment, one may hack the other's PNS to "control" their arm to flex and generate a slight shock. The "Human to Human Interface" enables learners to communicate directly with another's muscle via their PNS to tell their arm to flex. In the process, an electrical current produces a tingling feeling akin to hitting the "funny bone," as the TENS unit stimulates the other person's own ulnar nerve! (Griesar \& Eisen, 2019). 
For teachers wishing to conduct similar activities and even prepare pupils to practice engineering skills, both the company 'Backyard Brains' and Amazon offers an EMG starter kit designed for innovative hands-on learning. Students can upgrade the equipment to engage in new experiences, like controlling a robot arm. The "Human to Human Interface" equips pupils with the knowledge to answer, "How does your brain control your body?" (A. Eisen, personal interview, August 2020). (Griesar \& Eisen, 2019).

\section{"Drunk Goggles”}

The "Drunk Goggles" borrows from N.W. Noggin partner Portland Alcohol Research Center (PARC)'s activity using 'Fatal Vision' goggles produced by Innocorp. The goggles facilitate altered student perception to allow insight into the effects of alcohol intoxication. Learners gain first-hand experience of how alcohol shapes perception as they wear the goggles and try to walk straight along a line of duct tape. Would they feel comfortable driving intoxicated or as passengers with a drunk driver? Then, pupils use juggling or tennis balls to "shoot baskets" with and without the goggles. "Drunk Goggles" provide an opportunity for students to safely gain first-hand experience about the mind-altering effects of alcohol and a chance to ask about alcohol and other drugs. It is a memorable experience, and students often leave with an ability make more informed choices. (Griesar \& Leake, 2016).

\section{"Brain Game" and Other Worksheets}

N.W. Noggin tends to keep away from worksheets during classroom visits. However, available resources exist on the N.W. Noggin website to supplement learning for teachers to use in their classrooms if they so desire. The worksheets typically are visual in quality and diagram based. The "Brain Game" worksheet, for example, asks learners to label a diagram of different brain regions. These worksheets are accessible to anyone online. If teachers adopt them before and after outreach visits to test retention of 
How a Neuroscience Outreach Group Utilizing Art in S.T.E.M. Provides Cost-Effective Strategies in Tackling the United States Education Gap Grant Howard 49

neuroscience knowledge, sharing results with N.W. Noggin may help in program evaluation. (Giesar, 2015).

\section{The Art of Inquiry \& N.W. Noggin}

During a N.W. Noggin outreach visit, inquiry receives encouragement. Every activity enables learners to reflect and ask questions relevant to their lives and interests. Often, the focus of traditional learning and standardized testing asks students the questions. Allowing pupils to think more deeply and express their own ideas and interests empowers them by putting control of the learning process into their hands and allows them to feel comfortable exploring topics. The art of inquiry remains a fundamental part of the scientific process, as a researcher cannot reach a hypothesis without first posing a question.

Student inquiry also reveals a lot about student understanding; the more conceptual, complex, or unique questions help to develop expertise in innovative thinking. N.W. Noggin has been fortunate enough to visit North Middle School in Grants Pass, Oregon, two years in a row (2019-2020). Both times, students created a collection of thought-provoking questions about the brain. (Griesar, 2019; Griesar,

The following are examples from students from North Middle School for the year 2019:

- "If people are deaf what language do they think in?"

- "what happens when two emotions go against each other"

- "what happens inside the brain of old people with childhood trauma?"

- "Why can't the brain tell the difference between real and fake?"

- "Why do teenagers need so much sleep?"

The following are examples from students from North Middle School for the year 2020:

- "Brain Question: Why is your brain so light compared to your weight?"

- "How big is the brain? In [Social Sciences] we learned that Egyptians would pull the brain out through the nose when someone dies ???" 
- "How does your brain come up with your dreams?"

- "How many memories can our brain hold?"

- "How many sections are in the brain and what color is the brain? Does listening to classical music as a child make you smarter?"

If able, N.W. Noggin could collect inquiries from school visits multiple times to see how student knowledge and understanding evolves with each classroom visit. Collecting student questions could build support for inquiry-based student evaluation while simultaneously providing N.W. Noggin significant insight into the impact of their techniques. These inquiries ensure both the activities and the group continue to succeed in fulfilling their mission.

\section{N.W. Noggin Volunteers}

N.W. Noggin's grassroots success owes tremendous credit to its growing crew of dedicated volunteers. N.W. Noggin relies not only on communities to shape outreach experiences but volunteers as well. Like K-12 scholars, volunteers bring their own unique experience and expertise to each classroom visit. The exact crew rarely make up N.W. Noggin each time, save for Dr. Griesar and Leake, so outreach experiences remain exceptional, both for the K-12 students and for outreach volunteers. Volunteers always learn new information and gain new perspectives, both from each other and K-12 scholars.

With N.W. Noggin, volunteers obtain first-hand teaching experiences as they answer student inquiries and lead activities. They are always busy on their feet to provide an accessible educational environment and engaging learning opportunities. The personal introduction, for volunteers, is like an improvisational theater activity, useful in real-life application (i.e., teaching, thesis dissertations).

Volunteers must think quickly and stay on their toes for when a student has a question that fits their area of expertise. N.W. Noggin also offers a powerful, immersive chance to practice public speaking without judgment or formal, standardized assessment, an opportunity rarely available during or after college. 
Answering community inquiries puts volunteers on the frontline in the battle against disinformation. "Brain myths" are rampant and students bring up important questions or points where they want clarification. Even if a volunteer cannot answer a question, odds are another volunteer's expertise will address the subject matter. If not, rest assured! Dr. Griesar releases open-access blog posts answering any inquiries in an enjoyable and informative style with plenty of additional resources. With N.W. Noggin, few questions are left unaddressed. Taking on student inquiries also informs volunteers, some of whom actively participate in research, of community interests and concerns. Knowledge of community needs helps volunteers in deciding which communities to serve in their profession and even with networking skills. Volunteers may connect with other volunteers to work on collaborative projects or community members and form lasting bonds.

Outreach with N.W. Noggin provides the chance for volunteers to be S.T.E.A.M. representatives and act as role models. Considering disparities within S.T.E.M., it remains imperative that underserved learners see themselves within the N.W. Noggin community. Volunteers offer these pupils a real-life example of someone like them succeeding in neuroscience while also providing advice and insight they might not otherwise receive. The closeness in age may comfort K-12 scholars who often share their goals, interests, concerns and questions and thus be more inclined to engage in learning.

Plus, N.W. Noggin outreach is an enjoyable way to give back to the community while getting a break from school or work! Volunteers get to create art with students and community members, learn new information about their brains, and discuss their passions and interests with people from various walks of life. Everyone leaves with something, whether a noggin full of new knowledge, a colorful neuron to add to their collection, a new friend or work connection, and a big smile and well-deserved dopamine rush. N.W. Noggin is a brilliant way to build relevant expertise while having a blast. 
How a Neuroscience Outreach Group Utilizing Art in S.T.E.M. Provides Cost-Effective Strategies in Tackling the United States

\section{Works Cited}

Ali, M. (2014). Growing the Gifts of STEM for Children with Dyslexia. Learning Ally. https://learningally.org/Blog/growing-gifts-stem.

Banyai, I., \& Griesar, W. (2014). ZOOM Sequence Activity. https://N.W.noggin.org/wpcontent/uploads/2014/09/N.W.noggin-zoom-activitypdf.pdf.

Baxter, P., Ashurt, E., Read, R., Kennedy, J., \& Belpaeme, T. (2017) Robot education peers in a situated primary school study: Personalisation promotes child learning. PLOS ONE, 12(5). https://journals.plos.org/plosone/article?id=10.1371/journal.pone.0178126

Brandes, M., Howard, C., Galvan-Bravo, M., Eisen, A., Kiersarsky, S., \& Griesar, W. (2019). Reflections on Chicago. https://N.W.noggin.org/2019/11/11/sfn-reflections/

Bugg, J.M., \& McDaniel, M.A. (2012). Selective Benefits of question self-generation and answering for remembering expository text. Journal of Psychology, 104, 922-931. https://psycnet.apa.org/buy/2012-13976-001

Carnevale, A., Smith, N., \& Strohl, J. (2013). Recovery: Job Growth and Education Requirements Through 2020. Georgetown Public Policy Institute. https://cew.georgetown.edu/wpcontent/uploads/2014/11/Recovery2020.SR_.Web_.pdf

Cook, W. \& McGreevy-Nichols, S. (2005). Benefits of Dance Education in the Middle School Setting. Journal of Dance Education, 5(1), 28-30. https://www.tandfonline.com/doi/abs/10.1080/15290824.2005.10387280

Črnčec, R., Wilson, S., \& Prior, M. (2006). Cognitive and Academic Benefits of Music to Children: Facts and Fiction. An International Journal of Experimental Educational Psychology, 26(4), 579-594. https://www.tandfonline.com/doi/abs/10.1080/01443410500342542

Cutcher, A., \& Boyd, W. (2016). Preschool Children, Painting and Palimpset: Collaboration as Pedagogy, 
How a Neuroscience Outreach Group Utilizing Art in S.T.E.M. Provides Cost-Effective Strategies in Tackling the United States

Practice and Learning. The International Journal of Art \& Design Education, 37(1), 1-14. https://onlinelibrary.wiley.com/doi/abs/10.1111/jade.12113

Dolgun, T.O. (2018). Music Therapy in ADHD and Autism. IOSR Journal of Humanities and Social Science (IOSR-JHSS), 23(7), pg.90-96. https://www.researchgate.net/publication/326710276_Music_Therapy_in_ADHD_and_Autism

Dunn, C., Rabren, K. S., Taylor, S. L., \& Dotson, C. K. (2012). Assisting Students With HighIncidence Disabilities to Pursue Careers in Science, Technology, Engineering, and Mathematics. Intervention in School and Clinic, 48(1), 47-54. https://journals.sagepub.com/doi/10.1177/1053451212443151

Endecott, M., \& Griesar, W. (2019). Gray Matter in Grants Pass!.

https://N.W.noggin.org/2019/03/07/graymatter-in-grants-pass/

Eisen, A., \& Griesar, W. (n.d.). Resource: Brain Hacking is Electric! https://N.W.noggin.org/brainhacking-

is-electric/

Estrad, W. (2018). 6 Critical Thinking Skills You Need to Master Now. Rasmussen College. https://www.rasmussen.edu/student-experience/college-life/critical-thinkingskills-to-master-now/

Faber, R. (2016). Dance and early childhood cognition: The Isadora Effect. Arts Education Policy Review 2016, 0(0), 1-11. https://www.tandfonline.com/doi/abs/10.1080/10632913.2016.1245166

Fatal Vission Goggles. https://www.fatalvision.com/product-category/alcohol-drugs/fatal-vision-goggles/ Foote, A., Gitomer, D., Melamed, L., Rosenblatt, E., Simmons, S., Sims-Gunenhause, A., \& Winner, E. (1992). ARTS PROPEL: A Handbook for Visual Arts. Educational Testing Service and the President and Fellows of Harvard College (on behalf of Project Zero, Harvard Graduate School of Education). 
How a Neuroscience Outreach Group Utilizing Art in S.T.E.M. Provides Cost-Effective Strategies in Tackling the United States

Fry, K. (2014). Assessing inquiry learning: How much is a cubic metre?. Australian Primary Mathematic Classroom, 19(3), pgs 11-15. https://files.eric.ed.gov/fulltext/EJ1093367.pdf

Gasoi, E., \& Robbins Hoffman, S. (2017). How to Assess Arts Education - And Why You Should. Education Week. https://www.edweek.org/ew/articles/2017/10/04/how-to-assess-arts-education-and-why-you.html

Graham, M. (2019). Assessment in the visual arts: Challenges and possibilities. Arts Education Policy Review, 120(3), 175-183. https://www.tandfonline.com/doi/abs/10.1080/10632913.2019.1579131

Greene, J.P., Hitt, C., Kraybill, A., \& Bogulski, C.A. (2015). Learning from live theater: students realie gains in knowledge, tolerance, and more. Education Next, 15(1). https://www.educationnext.org/learning-live-theater/

Gregory „E., Hardiman, M., Yarmolinskaya, J., Rinne, L., \& Limb, C. (2013) Building creative thinking in the classroom: From research to practice. International Journal of Educational Research, 62, 43-50. https://www.sciencedirect.com/science/article/pii/S0883035513000669

Griesar, W. (2015). A Skyview Brain-Storm!. https://N.W.noggin.org/2015/04/17/a-skyview-brain-storm/ Griesar, W. \& Leake, J. (2014). After Image Final. https://N.W.noggin.org/wpcontent/uploads/2014/09/After-imagefinal.pdf

Griesar, W. \& Leake, J. (2014). After Image Slideshow. https://N.W.noggin.org/wpcontent/uploads/2014/09/afterimage-slideshow.pdf

Griesar, W. (2016). Brains in DC: Inspired Teaching at Turner and ITS. https://N.W.noggin.org/2016/05/01/brains-in-dc-inspired-teaching-at-turner-and-its/

Griesar, W. (2020). Can a brain use all of the parts at once?. https://N.W.noggin.org/2020/02/24/can-abrain-use-all-of-its-parts-at-once/

Griesar, W. (2015). Day Three @ Skyview: Neurotransmitters and Drugs. https://N.W.noggin.org/2015/04/02/day-three-skyview-neurotransmitters-and-drugs/ 
Griesar, W. \& Leake, J. (2020). Found Neuron Project. https://N.W.noggin.org/wpcontent/uploads/2020/06/FoundNeuron-Project.pdf

Griesar, W. (2015). Giant neurons @ McCoy: Day Two. https://N.W.noggin.org/2015/05/11/giantneuronsmccoy-day-two/

Griesar, W. (2015). Gray matter @ McCoy. https://N.W.noggin.org/2015/05/04/noggin-mccoy/ Griesar, W. (n.d.). How to 3D Print a Brain. https://N.W.noggin.org/how-to-3d-print-a-brain/ Griesar, W. \& Leake, J. (2016). Igniting interest with Blaze and Brains!. https://N.W.noggin.org/2016/06/12/ignitinginterest-with-blaze-and-brains/

Griesar, W. (2014). LESSON: Lobes of the Brain. https://N.W.noggin.org/wpcontent/uploads/2014/09/Lobes-Lesson-and-MindMaps-Project1.pdf

Griesar, W. \& Leake, J. (n.d.). MISSION STATEMENT. https://N.W.noggin.org/about-noggin/missionstatement/

Griesar, W. \& Leake, J. (2016). Neuron Gelatin Prints. https://N.W.noggin.org/wpcontent/uploads/2016/10/NeuronGelatin-Prints.pdf

Griesar, W. (2015). Neurons on Day Two @ Skyview. https://N.W.noggin.org/2015/03/27/neurons-onday-

two-skyview/

Griesar, W. \& Leake, J. (2018). N.W. Noggin Brain Map Project. https://N.W.noggin.org/wpcontent/uploads/2018/11/BRAIN-MAP-lesson-plan.pdf 
Griesar, W. \& Leake, J. (2014). Pipe Cleaner Neurons. https://N.W.noggin.org/wpcontent/uploads/2014/09/Pipe-

Cleaner-Neuron-ProjectBackground.pdf

Griesar, W. (n.d.). RESOURCE: How do neurons send electrical messages? https://N.W.noggin.org/resources/discover-how-do-neurons-send-electricalmessages/

Griesar, W. \& Leake, J. (2020). Sewing Memories, \& Brains. https://N.W.noggin.org/2020/02/14/sewingmemoriesbrains/

Griesar, W. (2015). Sheep Brain Dissection Guide. https://N.W.noggin.org/wpcontent/uploads/2014/09/Brain-dissection.pdf

Griesar, W. (2020). The Brains at Brain Fair.

Retrieved from https://N.W.noggin.org/2020/03/08/the-brains-at-brain-fair/

Griesar, W. (n.d.). What is N.W. Noggin..?. https://N.W.noggin.org/about-noggin/noggin/

Gullatt, Y., \& Jan, W. (2003). How Do Pre-Collegiate Academic Outreach Programs Impact College-Going among Underrepresented Students?. The Pathways to College Network. https://www.researchgate.net/publication/200031183_How_Do_PreCollegiate_Academic_Outreach_Programs_Impact_CollegeGoing_Among_Underrepresented_Students

Hanson, E. (2009). The Residential School System. Indigenous Foundations. http://indigenousfoundations.arts.ubc.ca/the_residential_school_system/

Hardiman, M. (2018). The Wiley International Handbook of Educational Foundations., John Wiley \& Sons, Inc., pgs.207-227.

Herro, D., \& Quigley, C. (2017). Exploring teachers' perceptions of STEAM teaching through 
How a Neuroscience Outreach Group Utilizing Art in S.T.E.M. Provides Cost-Effective Strategies in Tackling the United States

professional development: Implications for teacher educators. Professional Development in Education, 43(3), 416-438. https://eric.ed.gov/?id=EJ1141931

Hwang, J., \& Taylor, J. (2016). Stemming on STEM: A STEM Education Framework for Students with Disabilities. Journal of Science Education for Students with Disabilities, 19(1), 3949. https://scholarworks.rit.edu/jsesd/vol19/iss1/4/

Hughes, S. (2009). Leadership, management and sculpture: how arts based activities can transform learning and deepened understanding. Reflective Practice, 10(1), 77-90. https://www.tandfonline.com/doi/abs/10.1080/14623940802652854

Hunt, B.R., Allgood, K., Sprokes, C., \& Whitman, S. (2013). Metrics for the Systematic Evaluation of Community-Based Outreach. Journal of Cancer Education, 28(4), 633-638. https://pubmed.ncbi.nlm.nih.gov/23857186/

Janzen, T.B., \& Thaut, M.H. (2018). Rethinking the role of music in neurodevelopment of autism spectrum disorder. Society for Education, Music and Psychology Research: Music \& Science, 1-18. https://journals.sagepub.com/doi/pdf/10.1177/2059204318769639

Kafai, Y.B., \& Burke, Q. (2015). Constructionist Gaming: Understanding the Benefits of Making Games for Learning. Educational Psychologist, 50(4), 313-334. https://www.tandfonline.com/doi/full/10.1080/00461520.2015.1124022

Kaimal, G., Ray, K., \& Muniz, J. (2016). Reduction of Cortisol Levels and Participants' Responses Following Art Making. Art Therapy, 33(2), pgs.74-80. https://www.tandfonline.com/doi/full/10.1080/07421656.2016.1166832?journalCode=uart 20 
How a Neuroscience Outreach Group Utilizing Art in S.T.E.M. Provides Cost-Effective Strategies in Tackling the United States

Kang, S.H.K., \& Pashler, H. (2012). Learning Painting Styles: Spacing is Advantageous when it Promotes Discriminative Contrast. Applied Cognitive Psychology, 26(2012), 97-103. https://onlinelibrary.wiley.com/doi/abs/10.1002/acp.1801

Kozol, J. (2005). The shame of the nation: The restoration of apartheid schooling in America. Crown Trade Paperbacks/Crown Publishers.

Krom, C.L., \& William, S.V. (2012). Tell me a story: Using creative writing in introductory accounting courses to enhance and assess student learning. Journal of Accounting Education, 29(2011), 234-249. https://www.sciencedirect.com/science/article/abs/pii/S0748575112000334

Lane, D., \& Griesar, W. (2019). Brain-casting, on a budget!. ://N.W.noggin.org/2019/10/03/brain-casting-on-a-budget/

Leake, J. (2017). Brush strokes and brains: N.W. Noggin takes STEAM to a higher level. SciArt Initiative. https://www.sciartmagazine.com/brush-strokes--brains-N.W.-noggin-takessteam-to-a-higher-level.html

Lorimer, M.R. (2011). Arts-Infused Learning in Middle Level Classrooms. Journal for Learning through the Arts, 7(1). https://escholarship.org/uc/item/0hp6g86s

Lutfig, R.L. (1994). The Schooled Mind: Do the Arts Make a Difference? An Empirical Evaluation of the Hamilton Fairfield SPECTRA+ Program, 1992-93. Hamilton Fairfield Arts Association.

Madae, J. (2012). How art, technology, and design inform creative leaders. [Video]. TedTalks. https://www.ted.com/talks/john_maeda_how_art_technology_and_design_inform_creative _leaders/up-next?language=en 
How a Neuroscience Outreach Group Utilizing Art in S.T.E.M. Provides Cost-Effective Strategies in Tackling the United States

McConnell, E., Townsley, K., \& Griesar, W. (n.d.). ASSESSMENT: How do we know how we're doing?. https://N.W.noggin.org/resources/feedback/

Messmore, A.B. (1996). "Measuring the Impact of Grassroots Outreach.” Science Communication, 17(4), pgs.430-442. https://journals.sagepub.com/doi/10.1177/1075547096017004003

Miyamoto, K., Leake, J., \& Griesar, W. (2016) RESOURCE: STEAM Art Projects. https://N.W.noggin.org/resources/resource-arts-integration/

Muller, C.L., Roberts, S., Wilson, R.C., Remedios, J.J, Illingworth, S., Graves, R., Trent, T., Henderson, J., Wilkinson, J., Wilkinson, M., \& Desai, A. (2013). The Blue Marble: a Model for Primary School STEM Outreach. Physics Education, 48(2), pgs.176-183. https://iopscience.iop.org/article/10.1088/0031-9120/48/2/176

Perignat, E., \& Katz-Buonincontro, J. (2019). STEAM in practice and research: An integrative literature review. Thinking Skills and Creativity, 31, 31-43.

https://www.sciencedirect.com/science/article/abs/pii/S1871187118302190

Phillips, F. (1997). Evaluating Arts Education. Grantmakers in the Arts Newsletter, 8(2), 26-30. https://www.giarts.org/article/evaluating-arts-education

Pollock, I., Murray, J., \& Yeager, B. (2017). Brain jam - STEAM learning through Neuroscience-themed game development. Proceedings of the Second International Conference on Game Jams, Hackathons, and Game Creation Events. pgs 15-21. https://dl.acm.org/doi/10.1145/3055116.3055122

Racial/Ethnic Distribution of Bachelor's Degrees in the Humanities. (2017). https://www.amacad.org/humanities-indicators/higher-education/racialethnic-distributionbachelors-degrees-humanities

Raven, N. (2015). A framework for outreach evaluation plans. Research in Post-Compulsory Education, 
How a Neuroscience Outreach Group Utilizing Art in S.T.E.M. Provides Cost-Effective Strategies in Tackling the United States

20(2), pgs 245-262. https://www.tandfonline.com/doi/abs/10.1080/13596748.2015.1030264

Rinne, L., Gregory, E., Yarmolinskaya, \& Hardiman, M. (2011). Why Arts Integration Improves LongTerm Retention of Content. Mind, Brain, and Education, 5(2), 80-96. https://onlinelibrary.wiley.com/doi/abs/10.1111/j.1751-228X.2011.01114.X

Robertson, S. (2014). STEM Snapshot. Office of Science and Technology Policy. http://www.floridarti.usf.edu/resources/format/pdf/STEM\%20Snapshot.pdf

Rose, D., Bartoli, J., \& Heaton, P. (2018) Learning a musical instrument can benefit a child with special education needs. Psychomusicology: Music, Mind, and Brain, 28(2), 71-81. https://psycnet.apa.org/record/2018-31525-001

Rosen, R.J. (2013). What Neurons Look like (as Drawn by Students, Grad Students, and Professors). The Atlantic. https://www.theatlantic.com/technology/archive/2013/05/what-neurons-look-likeas-drawn-by-students-grad-students-and-professors/276446/

Segarra, V., Natalizio, B., Falkenberg, C.V., \& Pulford, S. (2018). STEAM: Using the Arts to Train WellRounded and Creative Scientists. Journal of Microbiology and Biology Education, 19(1). https://www.researchgate.net/publication/324879888_STEAM_Using_the_Arts_to_Train_WellRounded_and_Creative_Scientists

Shaw, D. \& Griesar, W. (2016). Making a pipe cleaner neuron... https://N.W.noggin.org/wpcontent/uploads/2016/04/How-to-make-a-pipe-cleanerneuron.pdf

Shaw, D. \& Griesar, W. (2018). Brain Map Project. https://N.W.noggin.org/wpcontent/uploads/2018/12/MAKE-Brain-Map.pdf

Shaw, D. \& Griesar, W. (2018). Neuron Gelatin Prints. https://N.W.noggin.org/wpcontent/uploads/2018/12/MAKE-Neuron-GelatinPrints.pdf

Shaw, D. \& Griesar, W. (2018). Plaster Brain Lesson Plan. https://N.W.noggin.org/wp- 
How a Neuroscience Outreach Group Utilizing Art in S.T.E.M. Provides Cost-Effective Strategies in Tackling the United States

content/uploads/2018/12/MAKE-Plaster-Brains.pdf

Siekmann, G. \& Korbel, P. (2016). Defining “STEM” Skills: Review and Synthesis of the Literature. Support Document 1. National Centre for Vocational Education Research (NCVER). https://eric.ed.gov/?id=ED570655

Struyf, J. \& Blockeel, H. (2010). Relational Learning. Encyclopedia of Machine Learning 2010 Edition. https://link.springer.com/referenceworkentry/10.1007\%2F978-0-387-30164-8_719\#howtocite

Thill, S. (2010). Mindflex Hack Turns Brain Waves Into Music. Wired. https://www.wired.com/2010/10/robert-schneider-teletron/

Thuneberg, H., Salmi, H., \& Bogner, F. (2018). How creativity, autonomy and visual reasoning contribute to cognitive learning in a STEAM hands-on inquiry-based math module. Thinking Skills and Creativity, 29, 153-160. https://www.sciencedirect.com/science/article/pii/S1871187118301159

Trechles, A.M. (2012). Creative Writing, Problem-Based Learning, and Game-Based Learning Principles. Presented at the International Society for Technology in Education (ISTE) Conference June 2012. https://files.eric.ed.gov/fulltext/ED543910.pdf

Uluay, G. \& Dogan, A. (2016). Pre-Service Teachers' Practices towards Digital Game Design for Technology Integration into Science Classrooms. Universal Journal of Education Research, 4(10), pgs 2483-2498. https://files.eric.ed.gov/fulltext/EJ1116376.pdf

Varner, J. (2014). Scientific Outreach: Toward Effective Public Engagement with Biological Science. BioScience, 64(4), 333-340. https://academic.oup.com/bioscience/article/64/4/333/248218

Vescolani, B., \& Williams, S. (2014). Final Program Report: Proceedings: Community STEM Outreach Program: A Local Model for National Impact. The Office of Naval Research. https://apps.dtic.mil/dtic/tr/fulltext/u2/a598380.pdf

Watermeyer, R. (2012). Confirming the legitimacy of female participation in science, technology, 
How a Neuroscience Outreach Group Utilizing Art in S.T.E.M. Provides Cost-Effective Strategies in Tackling the United States

engineering and mathematics (STEM): evaluation of a UK STEM initiative for girls. British Journal of Sociology of Education, 33(5), 679-700.

https://www.tandfonline.com/doi/abs/10.1080/01425692.2012.678751

Wandari, G. A., Wijaya, A. F. C., \& Agustin, R. R. (2018). The Effect of STEAM-based Learning on Students' Concept Mastery and Creativity in Learning Light And Optics. Journal of Science Learning, 2(1), 26-32.

https://www.researchgate.net/publication/333243589_The_Effect_of_STEAMbased_Learning_on_Students\%27_Concept_Mastery_and_Creativity_in_Learning_Light_And_O ptics

Winner, E. \& Leekam, S. (1991/96). Distinguishing irony from deception: Understanding the speaker's Second-order intention. British Journal of Developmental Psychology, 9(2), pgs.257-270. http://citeseerx.ist.psu.edu/viewdoc/download?doi=10.1.1.822.6943\&rep=rep1\&type=pdf

Wolf, D.P., \& Pistone, N. (1990). Taking Full Measure: Rethinking Assessment Through the Arts. College Entrance Examination Board.

Yawson, N. A., Amankwaa, A. O., Tali, B., Shang, V. O., Batu, E. N., Asiemoah, K., Jr, Fuseini, A. D., Tene, L. N., Angaandi, L., Blewusi, I., Borbi, M., Aduku, L. N., Badu, P., Abbey, H., \& Karikari, T. K. (2016). Evaluation of Changes in Ghanaian Students' Attitudes Towards Science Following Neuroscience Outreach Activities: A Means to Identify Effective Ways to Inspire Interest in Science Careers. Journal of undergraduate neuroscience education : JUNE : a publication of FUN, Faculty for Undergraduate Neuroscience, 14(2), A117-A123. https://www.ncbi.nlm.nih.gov/pmc/articles/PMC4917342/ 